\title{
Differentiating Glioblastomas from Solitary Brain Metastases: An Update on the Current Literature of Advanced Imaging Modalities
}

\author{
Austin-John Fordham ${ }^{1}$, Caitlin-Craft Hacherl ${ }^{1}$, Neal Patel ${ }^{1}$, Keri Jones ${ }^{2}$, Brandon Myers ${ }^{2}$, Mickey Abraham ${ }^{3}$ and \\ Julian Gendreau ${ }^{4, *}$ \\ 1 School of Medicine, Mercer University School of Medicine, Savannah, GA 31404, USA; \\ AustinJohn.Fowler.fordham@live.Mercer.edu (A.-J.F.); Caitlin.Elizabeth.Hacherl@live.mercer.edu (C.C.-H.); \\ neal.atul.patel@live.mercer.edu (N.P.) \\ 2 Graduate Medical Education, Eisenhower Army Medical Center, Augusta, GA 30905, USA; \\ keri.l.jones18.ctr@mail.mil (K.J.); brandon.1.myers20.mil@mail.mil (B.M.) \\ 3 Department of Neurosurgery, University of California San Diego, La Jolla, CA 92093, USA; \\ mabraham@health.ucsd.edu \\ 4 Department of Biomedical Engineering, Johns Hopkins Whiting School of Engineering, \\ Baltimore, MD 21218, USA \\ * Correspondence: jgendre1@jhu.edu
}

check for updates

Citation: Fordham, A.-J.; Hacherl, C.-C.; Patel, N.; Jones, K.; Myers, B.; Abraham, M.; Gendreau, J.

Differentiating Glioblastomas from

Solitary Brain Metastases: An Update on the Current Literature of Advanced Imaging Modalities. Cancers 2021, 13, 2960. https:/ / doi.org/10.3390/cancers13122960

Academic Editor: Jorn Fierstra

Received: 14 May 2021

Accepted: 9 June 2021

Published: 13 June 2021

Publisher's Note: MDPI stays neutral with regard to jurisdictional claims in published maps and institutional affiliations.

Copyright: (C) 2021 by the authors. Licensee MDPI, Basel, Switzerland. This article is an open access article distributed under the terms and conditions of the Creative Commons Attribution (CC BY) license (https:/ / creativecommons.org/licenses/by/ $4.0 /)$.
Simple Summary: The process of differentiating glioblastomas from solitary brain metastases is often difficult using traditional magnetic resonance imaging alone. In the past two decades, much progress has been made in devising advanced imaging modalities for the purpose of ascertaining more data on these intracranial tumors to help neuroradiologists in differentiating the two pathologies. In addition to the data provided by dynamic susceptibility contrast imaging and magnetic resonance spectroscopy, more innovative modalities now include diffusion tensor imaging and neurite orientation dispersion and density imaging. Radiomic analysis protocols and machine learning algorithms are being continually optimized to increase the accuracy of diagnosis by utilizing multiple different imaging protocols per patient. In this review, we provide an update on these advanced imaging modalities by reviewing the most up-to-date and current evidence.

Abstract: Differentiating between glioblastomas and solitary brain metastases proves to be a challenging diagnosis for neuroradiologists, as both present with imaging patterns consisting of peritumoral hyperintensities with similar intratumoral texture on traditional magnetic resonance imaging sequences. Early diagnosis is paramount, as each pathology has completely different methods of clinical assessment. In the past decade, recent developments in advanced imaging modalities enabled providers to acquire a more accurate diagnosis earlier in the patient's clinical assessment, thus optimizing clinical outcome. Dynamic susceptibility contrast has been optimized for detecting relative cerebral blood flow and relative cerebral blood volume. Diffusion tensor imaging can be used to detect changes in mean diffusivity. Neurite orientation dispersion and density imaging is an innovative modality detecting changes in intracellular volume fraction, isotropic volume fraction, and extracellular volume fraction. Magnetic resonance spectroscopy is able to assist by providing a metabolic descriptor while detecting variable ratios of choline/ $\mathrm{N}$-acetylaspartate, choline/creatine, and N-acetylaspartate/creatine. Finally, radiomics and machine learning algorithms have been devised to assist in improving diagnostic accuracy while often utilizing more than one advanced imaging protocol per patient. In this review, we provide an update on all the current evidence regarding the identification and differentiation of glioblastomas from solitary brain metastases.

Keywords: arterial spin labelling; diffusion tensor imaging; diffusion-weighted imaging; dynamic susceptibility contrast; glioblastoma; intracranial; machine learning; magnetic resonance; metastasis; neurite orientation dispersion density 


\section{Introduction}

Gliomas are found to account for approximately $25 \%$ of all adult brain tumors. They are considered the most rapidly growing malignancies of the central nervous system, with glioblastoma multiforme comprising more than $50 \%$ of all gliomas [1]. In addition, solitary brain metastases are becoming increasingly more common as the elderly population continues to increase in number throughout the world. Additional diagnoses of intracranial metastases are also being made due to the increased use of imaging for clinical assessment. Therefore, differentiating these two diagnoses is becoming a more prominent and challenging issue in patient care for neuroradiologists and neurosurgeons [2-4]. In many cases, a biopsy is performed for histological confirmation, even if there is a history of known malignancy [5].

Accurate tumor diagnosis and classification is essential early on in a patient's clinical assessment, as treatment modalities differ significantly between the two diseases. Patients with glioblastoma typically undergo gross total resection and treatment consisting of both radiotherapy and a chemotherapeutic course of temozolomide [6]. Metastases are commonly managed with stereotactic radiosurgery or open operative resection with postoperative whole-brain radiotherapy depending on the size and location of the disease [7]. This is in addition to the evaluation for the possibility of systemic cancer if the patient has no known prior history. Having the earliest detection and differentiation of the patient's disease is paramount for optimizing clinical outcomes.

Initially, imaging modalities for discerning these diseases was limited to conventional high-resolution magnetic resonance imaging (MRI) with a contrasting agent such as gadolinium for optimal characterization. However, this imaging is limited, as both pathologies are largely characterized by having peritumoral hyperintensity and FLAIR signal (Figure 1) [8-15]. In the past decade, advanced imaging modalities were developed to augment traditional MRI in improving diagnostic accuracy. To date, an update on these novel imaging techniques and procedures has yet to be provided. Therefore, the goal of this review is to outline the most recent findings of newly developed and tested imaging systems by providing data on clinical trials, case series, and technical reviews. In addition, an overview of the physics and mechanisms of each modality will be discussed. 


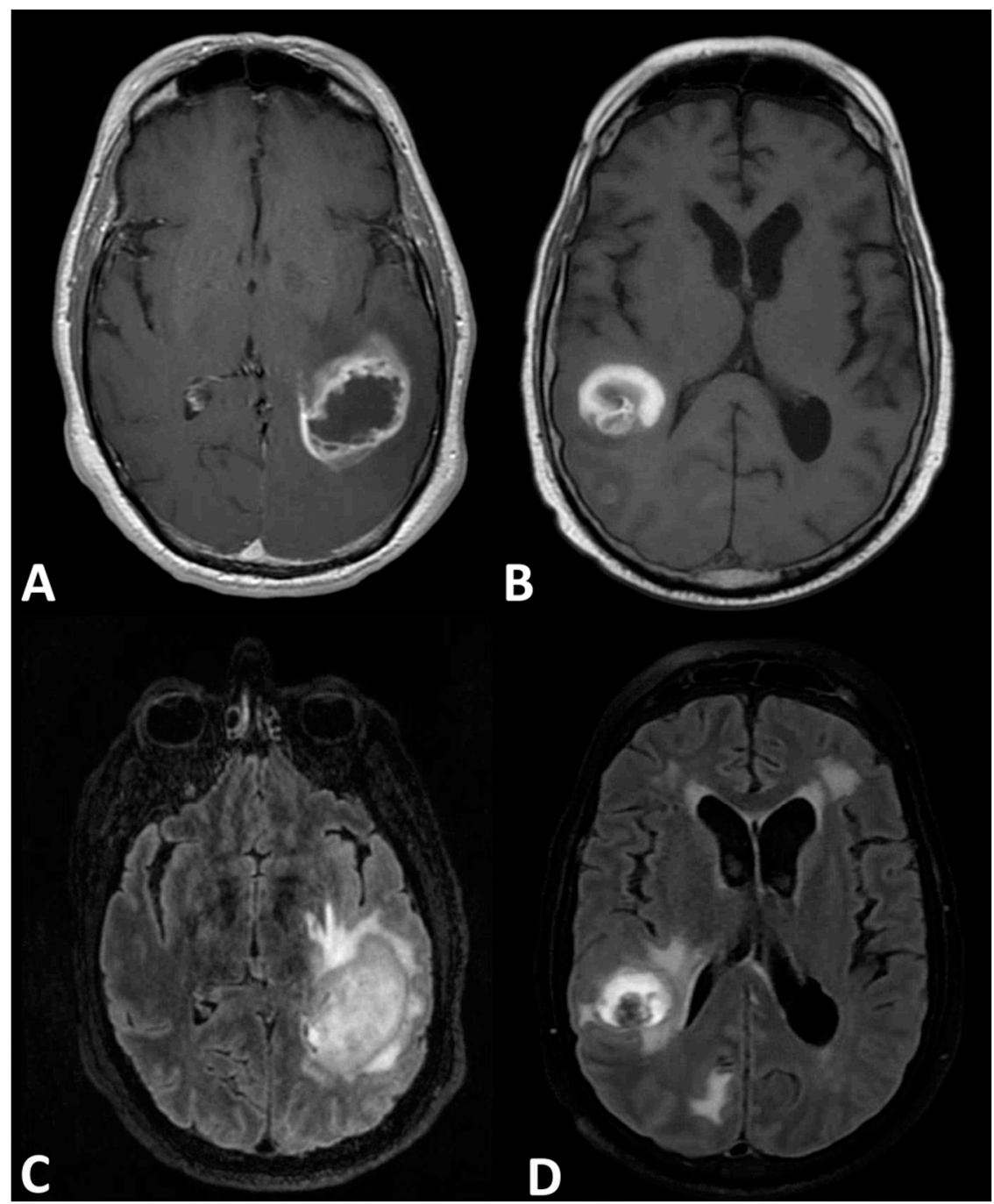

Figure 1. Magnetic resonance imaging. T1 imaging of a left temporal-parietal (A) glioblastoma and a left temporal-parietal (B) solitary intracranial metastasis both exhibiting ring-enhancing hyperintensity features with peritumoral hypointensity. T2 imaging of (C) a glioblastoma and a (D) solitary metastasis both characterized by peritumoral hyperintensity.

\section{Magnetic Resonance Imaging}

This technology is fundamental for initial evaluation of intracranial lesions and, additionally, is a basis for many of the advanced imaging modalities used for further characterization. During the imaging process, the patient lies supine and is placed inside powerful magnets producing magnetic fields. These fields align protons of the imaged tissue in the same direction as the magnetic fields in a parallel fashion. A radiofrequency is then applied, stimulating protons to spin out of equilibrium, which causes strain against the pull of the magnetic field. Sensors detect the energy emitted from these protons once this radiofrequency field is turned off and the protons relax [16]. These sensors generate an image at a much higher resolution than computed tomography and other radiographs. This allows for a more superior diagnostic accuracy of many intracranial lesions (Figure 2).

The T1-weighted and T2-weight MRI sequences describe two different relaxation times. T1 (longitudinal relaxation time) is the rate at which excited protons return to equilibrium and realign with the magnetic field. The T2 (transverse relaxation time) is the rate at which the spinning protons lose phase coherence among the nuclei spinning perpendicular to the main field. 

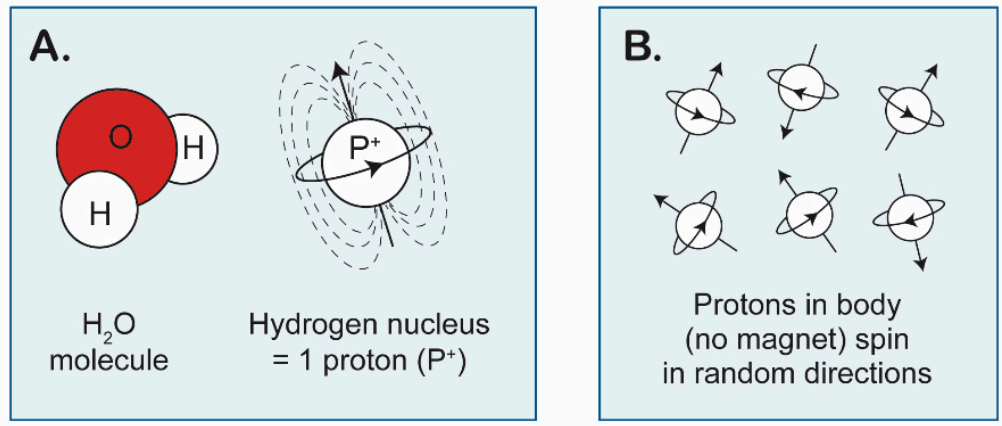

C.

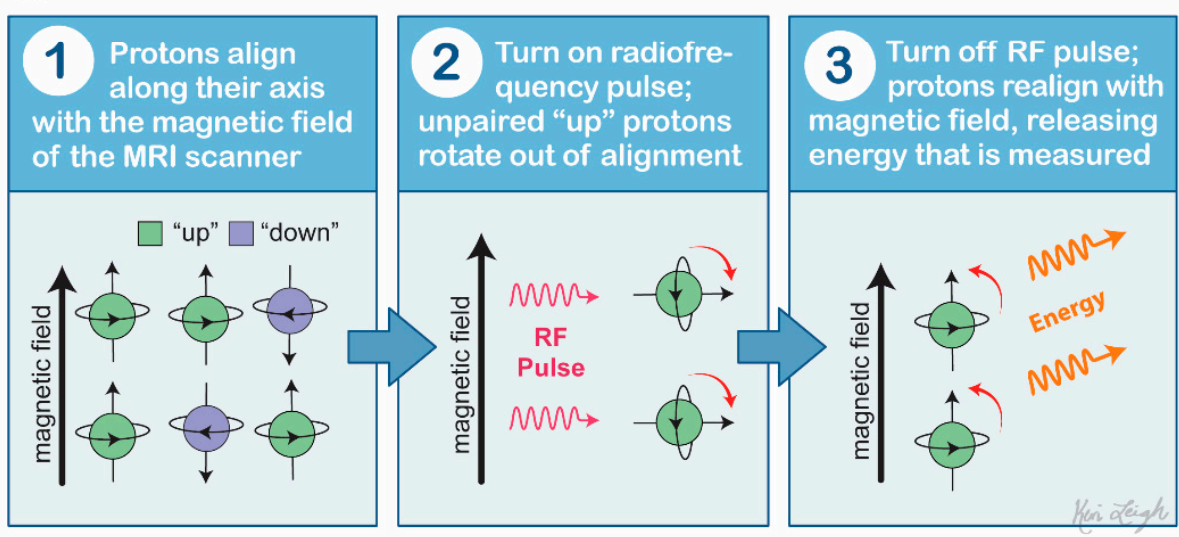

Figure 2. Mechanism of magnetic resonance imaging. (A) Hydrogen atoms are dispersed within the patient's tissue with intrinsic spin. (B) Hydrogen atoms are spinning in random direction without alignment with one another. (C) Protons align with the magnetic field in parallel fashion; after the application of a radiofrequency pulse, the protons realign with the magnetic field, releasing energy and generating a high-resolution image of the tissue.

Once the high-resolution MRI image is produced, both glioblastoma and metastases have similar features. They are both surrounded by a T2 signal hyperintensity that has been traditionally termed vasogenic edema. The nonenhancing hypointense area that surrounds the outer aspect of the tumor is peritumoral edema. This signal abnormality represents increased interstitial water due to capillary permeability and breakdown of the blood-brain barrier. Glioblastoma is infiltrative and tends to invade surrounding tissue and white matter tracts. It advances microscopically for several centimeters beyond the area of enhancement on imaging [5]. Therefore, in glioblastoma, peritumoral areas demonstrate not only increased interstitial water but also the possibility of scattered metastases, which is described as infiltrative edema [5]. This is in comparison with metastasis, which grows in an expansile manner, only displacing surrounding tissues and without infiltrative edema. This concept suggests that the most successful methods for accurately characterizing the lesion would focus and assess for peritumoral parameters [17]. Typical MRI has limited ability to detect these peritumoral changes; therefore, novel advanced MRI concepts are being developed to aid in this process (Table 1).

It is important to note that there is some evidence for differentiating the two diseases using conventional MRI alone. One study found that the ratio of the maximal diameter of the peritumoral area to the maximal diameter of the enhancing mass can be used to help distinguish between the two images. A lower ratio favors glioblastoma. Using a cutoff value of 2.35 , this achieves an accuracy of $68 \%$, sensitivity of $84 \%$, and specificity of $45 \%$ [18]. Relatively, there is increased water in the vasogenic edema of metastases when compared with glioblastoma resulting from the increased neoplastic cells in the latter. Therefore, there would be a theoretical decrease in signal area for glioblastoma when compared with metastases with fluid-attenuated inversion recovery (FLAIR) sequences. This method is 
suggested to have a sensitivity of $44 \%$ and specificity of $91 \%$ [10]. Metastases can generally be expected to involve the subcortical white matter and grey-white matter junction.

Table 1. Sensitivities and specificities of advanced imaging modalities for differentiating glioblastoma versus metastasis.

\begin{tabular}{|c|c|c|c|}
\hline Imaging Technique & Sensitivity & Specificity & Accuracy \\
\hline $\begin{array}{l}\text { Traditional MRI with ratio of peritumoral area to enhancing mass with a cutoff } \\
\text { value of } 2.35[18]\end{array}$ & $84 \%$ & $45 \%$ & $68 \%$ \\
\hline Decrease in FLAIR signal in glioblastoma compared with metastasis [10] & $44 \%$ & $91 \%$ & \\
\hline Dynamic susceptibility contrast perfusion using rCBV [19] & $90 \%$ & $91 \%$ & \\
\hline Both DWI and DTI [20] & $79.8 \%$ & $80.9 \%$ & \\
\hline Diffusion tensor imaging using a VEC threshold of 0.48 [21] & $100 \%$ & $83.3 \%$ & \\
\hline DTI parameters with DSC [22] & $60-91 \%$ & $55-100 \%$ & $98 \%$ \\
\hline MRS with LM13 class lipids and cutoff of $81 \mathrm{mM}$ [23] & $81 \%$ & $78 \%$ & $85 \%$ \\
\hline PET imaging with $\alpha$ [11C] methyl-l-tryptophan with kinetic tracer analysis [24] & & & $93 \%$ \\
\hline Machine learning algorithm with MRS and DSC data [25] & & & $98 \%$ \\
\hline Two-dimensional morphological feature extraction for DTI [26] & & & $97.9 \%$ \\
\hline
\end{tabular}

FLAIR—fluid-attenuated inversion recovery; rCBV—relative cerebral blood volume; VEC—extracellular volume fraction; DWI—diffusionweighted imaging; DTI—diffusion tensor imaging; DSC—dynamic susceptibility contrast; MRS—magnetic resonance spectroscopy; PET- positron emission tomography.

\section{Perfusion Magnetic Resonance Imaging}

\subsection{Dynamic Susceptibility Contrast-Enhanced Perfusion}

When traditional MR imaging is coupled with contrasting agents such as gadolinium, increased diagnostic accuracy is achieved [27]. Contrast agents are now found in largely $60 \%$ of MRI examinations performed for neurological disease [28]. Dynamic susceptibility contrast-enhanced perfusion (DSC) is one of the most widely used methods of MR perfusion imaging due to its efficacy, wide availability, and quick visualization times of $<1 \mathrm{~min}$ [29-34]. A succinct magnetic resonance signal is generated from this gadolinium contrast agent by tracking $\mathrm{T} 2 *$-weighted signal changes during the first pass of contrast [31]. A map of the cerebral blood volume (CBV) that outlines the vascularity of the tumor is created $[15,29]$. In some tumors, marked angiogenesis occurs, which produces increased relative peritumoral cerebral blood volume (rCBV) when compared with the surrounding brain parenchyma [35].

Unlike single brain metastases, glioblastoma presents with elevated rCBV due to increased cellular proliferation. Therefore, this allows DSC to be useful as a diagnostic tool $[13,36,37]$. In metastatic tumors, the peritumoral region is intrinsically normal parenchyma but edematous since metastases do not induce surrounding neoangiogenesis [38-43]. This edema is additionally suggested to provide local compression of blood flow, further decreasing rCBV when compared with glioblastoma $[44,45]$. Park et al. describe an autoencoder used for DSC that is found to be helpful in differentiating the two diseases by using perfusion patterns [46]. Increased rCBV is additionally suggested to be associated with worse clinical outcomes and shorter overall survivability due to its correlation with aggressive tumor growth in glioblastoma [30,47,48].

There is sizeable evidence from previous studies that supports the utility of rCBV as a diagnostic tool to differentiate the two lesions clinically. A meta-analysis by Suh et al. provided data that were statistically analyzed from 18 studies and included a total of 900 patients [19]. They found that DSC offered a high sensitivity of $90 \%(95 \% \mathrm{CI}=84-94 \%)$ and a specificity of $91 \%(95 \% \mathrm{CI}=84-95 \%)$ of detecting glioblastoma from metastases using rCBV. Neska-Matuszewska et al. found that brain metastases have significantly lower mean rCBVmax values, in addition to rCBV, when compared with glioblastoma [31].

Higher rates of inflow-based vascular-space-occupancy arteriolar CBV and relative arteriolar CBV are also found in glioblastoma. The peak height for peritumoral T2 lesions and signal intensity recovery were higher in glioblastoma than metastases [49]. Additional studies have found that optimizing MR protocols for acquiring percentage signal recovery 
(PSR) in addition DSC protocols with rCBV acquisition leads to even higher amounts of accuracy [50].

Despite its utility and widespread use for providing a discriminator using rCBV parameters, DSC does have some limitations. It has the potential for artifacts such as the presence of susceptibility artifacts from surgical hardware or bone-air interfaces near the skull base [30,34,51-53]. Large cortical veins and intraparenchymal hemorrhages can also be the etiology of artifacts [33,54-56]. To aid neuroradiologists in the successful application of DSC MRI, many organizations, such as the American Society of Functional Neuroradiology, have set forth guidelines of standardization to attain reproducible and satisfactory results [57]. These recommendations include inspecting signal-time curves for the presence of an appropriate signal drop to indicate a quality contrast bolus [58] and inspecting perfusion maps for bolus or processing errors [53].

\subsection{Dynamic Contrast-Enhanced Magnetic Resonance Perfusion}

Theoretically, contrast does not extravasate from blood vessels in the brain; however, in brain tumors, blood does extravasate out of the vasculature. This blood extravasation is measured by dynamic contrast-enhanced MR perfusion (DCE), which was developed in 1990 [59]. Improvements in data quality have since led to more complex second-generation models that are in use by radiologists today [60]. Similar to DSC, DCE provides information about tissue properties at the microvascular level. However, this is done by capturing serial T1-weighted images before, during, and after injecting a gadolinium-based contrast agent [33].

Following contrast agent injection, the resulting hemodynamic signals are dependent on the $\mathrm{T} 1$ relaxation time and increase (T1 shortening) due to the effects of the paramagnetic or gadolinium-based contrast agent [61]. A linear relationship between the magnetic resonance signal and the concentration of the contrast agent in the tissue results. This T1 shortening is the mechanism of tissue enhancement. To measure these signal changes as a function of time, T1-weighted images are captured rapidly and repeatedly [62]. The rate at which the contrast agent diffuses from the blood to the extravascular extracellular space is determined by tissue perfusion, capillary permeability, and capillary surface area [62].

Signal enhancement can be assessed semiquantitatively by analyzing signal intensity changes or quantitatively using pharmacokinetic modeling techniques to determine changes related to contrast agent concentration [62]. The leaking of contrast from the tumor vasculature allows the calculation of quantitative biomarkers, including the transfer constant (Ktrans), the fractional volume of the extravascular-extracellular space $\left(\mathrm{v}_{\mathrm{e}}\right)$, the rate constant (Kep), the fractional volume of the plasma space $\left(v_{p}\right)$, and the area under the curve (AUC) [63]. Ktrans is the biomarker most commonly used and has been shown to indicate permeability in patients with glioma $[33,64]$.

Clinically, this imaging is largely used in conjunction with other imaging modalities for lesion assessment. Jung et al. describe 26 patients with glioblastoma and 32 patients with metastatic brain lesions who underwent DCE imaging. They found that neither Ktrans nor $V_{p}$ was able to differentiate glioblastoma from brain metastases to any statistical significance [65]. However, they were able to differentiate hypervascular lesions, such as glioblastoma and melanoma metastases, from hypovascular metastases using the AUC and the log slope of the washout phase of the signal intensity time curve. Still, these metrics were unable to differentiate glioblastoma from melanoma metastasis. Conversely, Bauer et al. found that Ktrans was higher in patients with glioblastoma than in those with metastatic disease [22]. Zhao et al. found that in the tumor parenchyma, mean $\mathrm{V}_{\mathrm{e}}$ and initial AUC were significantly higher in primary central nervous system lymphoma and metastases than in high-grade gliomas $(p<0.003)$ [66]. Overall, there seems to be a lack of studies using DCE alone to discriminate between glioblastoma and brain metastasis. Therefore, it is more commonly used as an adjunct in conjunction with other imaging modalities at this time. 
With DCE, the ability to quantitatively analyze the blood-brain barrier and vascular permeability gives the user a different perspective compared with DSC and may offer a more complete assessment of brain tumor angiogenesis when used as an adjunct imaging modality [33]. DSC provides the benefit of removing T1 effects, and DCE the benefit of removing $\mathrm{T} 2$ * signal change effects when assessing the tumors.

\subsection{Arterial Spin Labeling}

Arterial spin labeling (ASL) is a noninvasive perfusion imaging technique that uses magnetically labeled arterial blood as a tracer in place of gadolinium-based contrast. This was created in 1992, as it was found to have the benefit of bypassing adverse events of traditional contrast $[67,68]$. This system works by utilizing the magnetic field of the MRI to magnetize blood just below the region of interest (often in the area of the neck for brain imaging), which is timed to occur at an interval before emitting the pulse frequency. Subsequently, this magnetized blood reaches the brain during the time of the pulse frequency and is already premagnetized. Therefore, the longitudinal magnetization of the blood flow is less than fully relaxed when compared with the stationary tissue. This results in a noninvasive perfusion image [69].

Several studies have shown that cerebral blood flow (CBF) with this modality offers accurate correlation with both CBV and actual vascular density from histological examination even without the use of traditional contrast [68,70-73]. It has also been found to be sensitive to changes in tumor perfusion specifically [74]. To date, there is indeed evidence concluding that noninvasive ASL techniques can effectively differentiate glioblastoma from primary CNS lymphomas and radionecrosis of the brain [75-77]. Direct studies using ASL methods to differentiate glioblastoma from metastases using signal intensity have shown diagnostic benefit; however, ASL-derived tumor blood flow is largely inconclusive on whether it reliably differentiates [78-80] in glioblastoma versus metastases specifically. ASL was found to reliably differentiate when coupled with DTI methods in one study [79].

\section{Diffusion Imaging}

\subsection{Diffusion-Weighted Imaging-Measurement of Apparent Diffusion Coefficient}

Diffusion-weighted imaging (DWI) was first introduced in 1984 as a form of conventional MRI that measures the diffusion rate of water within a given tissue without requiring extra equipment, contrast agents, or chemical tracers [81]. This method is inherently limited due to its inability to describe the degree of anisotropy or quantify information regarding structural orientation [82]. DWI is utilized to grade and differentiate tumors based on cellularity [83].

Water diffusion is based on the random Brownian motion of molecules due to thermal energy. In a completely uniform medium, water diffusion is said to be isotropic (the same in all directions), but in a multifaceted system, such as the human body, compartmentalization of water creates anisotropic (directional) diffusion [84]. When a temporary magnetic field is applied, the homogeneity of molecules can be dephased and then followed by a gradient in the opposite direction to rephase and restore signal. The protons that move between the dephasing and rephasing gradients contribute to the diffusion-weighted image [85]. The apparent diffusion coefficient (ADC) describes the magnitude of water diffusion in tissue [86]. With multiple DW images, ADC values can be determined by applying theoretical mathematical equations using variables such as the strength of the magnetic field along with initial signal intensity and signal intensity post-imaging [85].

The images obtained from DWI alone yield little diagnostic value in differentiating gliomas from metastases (Figure 3) [87-90]. However, one study provides evidence that tumor ADC values in malignant glioma are different from those in metastases by using 3 Tesla MRI equipment at a level that achieves statistical significance [11,91]. Texture analysis with ADC is also found to be a reliable differentiator [92]. Theoretically, models could be developed to examine the cellularity of intracranial lesions using DWI, and it would aid in differentiation. It has been suggested that a reduction in ADC values on 
imaging indicates higher cellularity, which could be useful in measuring whether or not there is tumor cellular invasion of the surrounding tissues. Several studies have studied this, comparing the peritumoral edema of metastases and high-grade glioma, and support this hypothesis [11,88,88,93-95].

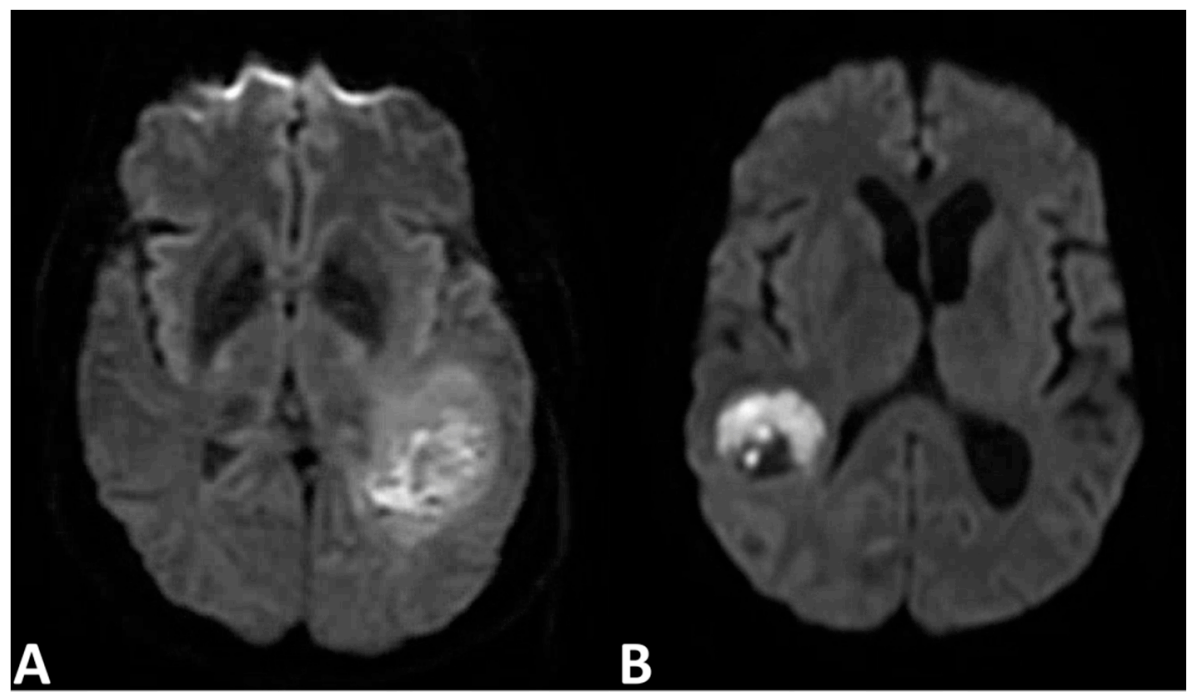

Figure 3. Diffusion-weighted imaging of (A) glioblastoma and (B) solitary intracranial metastasis with largely similar imaging features.

\subsection{Diffusion-Weighted Imaging-Exponential Measurements}

DWI signal intensity is actually influenced by intrinsic T2 properties of the brain parenchyma in addition to water diffusibility. Relative signal intensities from each source are difficult to characterize on DWI alone; therefore, the hyperintense signal on imaging is largely attributed to intrinsic T2 signal and is termed T2 "shine- through." The negative exponential value of ADC can be calculated using mathematical calculations of the workstation, and the T2 signal intensity can be removed from the tissue being imaged, thus creating a more accurate depiction of diffusion. This allows neuroradiologists to better characterize the tumor. Glioblastoma and metastases theoretically have different signal intensities on exponential DWI. Metastases display decreased signal intensity due to vasogenic edema, while glioblastoma displays intermediate signal intensity when compared with brain parenchyma $[96,97]$.

\subsection{Diffusion Tensor Imaging}

The dataset obtained from DWI can be utilized by an additional technique known as diffusion tensor imaging (DTI) [34]. This type of modeling, first described in 1994 [82,98], provides a method for indirectly measuring the complex neuroanatomical structure of white matter tracts in the brain and spinal cord by determining fiber tract orientation and is often color-coded on imaging (Figure 4) [99]. The direction of water molecule diffusion is acquired mathematically through the use of a $3 \times 3$ symmetric matrix, which can be expressed by its associated eigenvalues and eigenvectors [100]. The matrix represents an ellipsoid shape, which has been shown to be the best orientation for obtaining the most realistic simulation of water diffusion in white matter fiber tracts [101]. This elliptical depiction can be described as a type of tensor [102].

While DWI can be used to determine ADC values, this model is basic, as it assumes isotropic water diffusion (i.e., the same in all directions) [101]. In reality, water diffusion within white matter changes depending on the direction of measurement. Elements that have an effect on water diffusion in the white matter of the brain include myelin sheaths, cell membranes, structural directions, surrounding tissue types, and the level of permeability of these structures [99]. This means that water does not diffuse equally in all directions 
within the brain tissue, in the same way that a spherical drop of water in microgravity would. Instead, the water within white matter tracts diffuses in a certain direction, bound by these barriers.

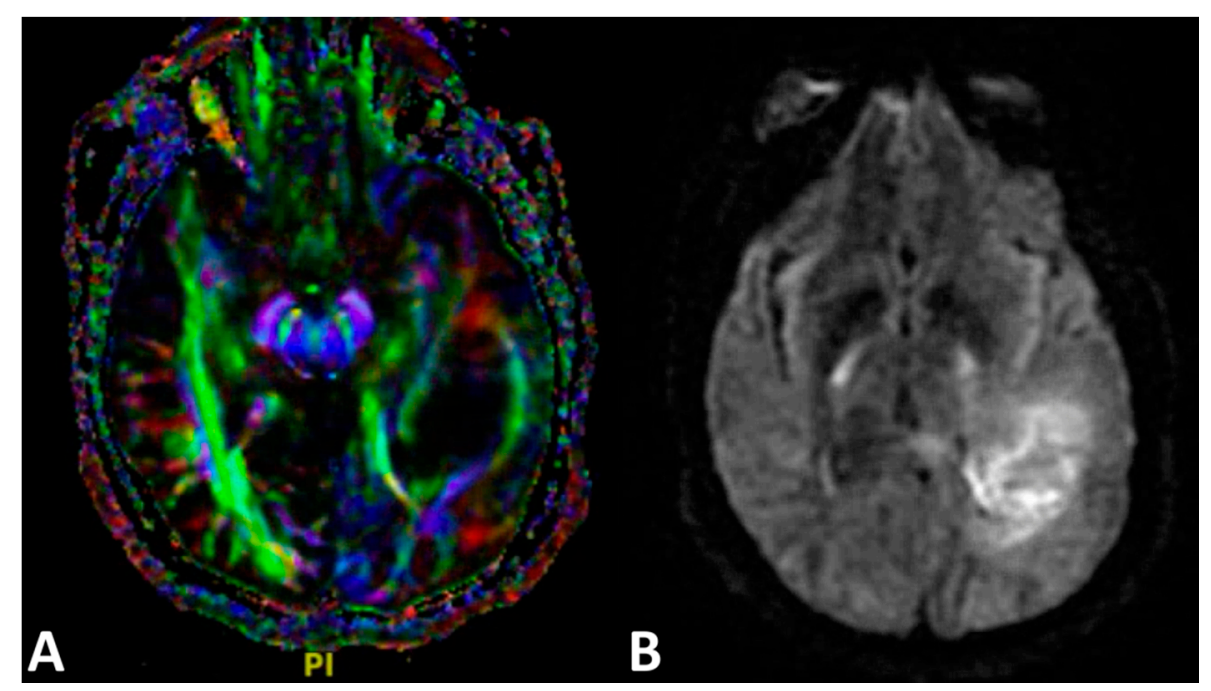

Figure 4. Diffusion tensor imaging. (A) Colored diffusion tensor imaging of a left temporal-parietal glioblastoma. Different neural fibers are displayed: transverse fibers (red), anteroposterior fibers (green), and craniocaudal fibers (blue) using tensor imaging features. (B) Noncolored diffusion tensor imaging of a glioblastoma.

With this in mind, it is easier to understand why an elliptical tensor model elongated parallel to white matter tracts is a more accurate diffusion model than a sphere or cube. It is also important to note that the tensor in this context is often referred to as a voxel. A voxel is the volume contained within a specific region of focus. Due to the tensor representing a three-dimensional (3-D) matrix, the voxel is a 3-D point in space containing all elements (in this scenario, the elements consist of brain tissue) of that space, and this is where the measurements are taken [103]. Analysis of each voxel can provide information on the tissue microstructure contained within.

The parameters given through arithmetical analysis of each tensor model include the mean diffusivity (MD), the fractional anisotropy (FA), and the fiber orientation mapping (tractography) [104]. FA measures the magnitude of the tensor's associated eigenvalues that can be attributed to anisotropic diffusion, which is equivalent to the direction of water diffusion [105]. In general, FA decreases in damaged tissues due to the disruption of directional water diffusion. The eigenvector correlated with the tensor model can be used to determine the orientation of tissue structure within the brain. This allows the connectivity of white matter fiber tracts to be mapped out voxel by voxel [106]. MD is a measure of the overall diffusion within a voxel. In damaged tissues, MD commonly increases secondary to increased permeability of the barriers to diffusion, such as the cell membrane and myelin sheath [107]. However, as with FA, this is not always the case and can depend on the specific region of the brain, disease pathology, and developmental conditions [108]. In the brain, FA is also a measure of white matter fiber integrity in addition to directionality $[109,110]$. FA is found to correlate with cell density, axonal structures, neuronal structures, vascularity, and fiber tracts [111-113]. It is still largely controversial whether increases in FA values are associated with tumors or vice versa $[114,115]$.

Investigators have found differences in infiltrative edema of glioblastoma versus vasogenic edema of metastases [116-118]. There is largely higher MD in the peritumoral edema than in infiltrative edema. This is due to the marked influx of water when compared with the cellular infiltrate of glioblastoma. Peritumoral FA is not significantly different between the two pathologies and is conflicting, likely due to the infiltrative edema having 
varying fractional compositions of normal white-grey matter, intracellular water, and tumor cellular infiltrates [5].

Jiang et al. performed a meta-analysis including a total of 9 studies with 193 patients having high-grade glioma and 141 patients with metastases [119]. They found a significant increase in FA of the peritumoral region in high-grade glioma when compared with single brain metastases (SMD $=0.47 ; 95 \% \mathrm{CI}, 0.22-0.71 ; p<0.01$ ). A significant decrease in $\mathrm{MD}$ of the peritumoral region was also found in high-grade glioma when compared with metastases (SMD $=-1.49 ; 95 \% \mathrm{CI},-1.91$ to $-1.06 ; p<0.01)$. Interestingly, no significant differences were detected in FA or MD within the intratumoral area of gliomas and metastasis.

In a more recent and much larger meta-analysis, Suh et al. included 14 studies and a total of 1143 patients to determine the diagnostic performance of DWI and DTI in differentiating high-grade glioma from metastases [20]. They found the average sensitivity and specificity of DWI and DTI in diagnosing high-grade gliomas from solitary metastatic lesions to be $79.8 \%$ (95\% CI, 70.9-86.4\%) and $80.9 \%$ (95\% CI, 75.1-85.5\%), respectively. Peritumoral heterogeneity on texture analysis has also been suggested to differentiate these two diseases in DTI; however, intratumoral texture does not differentiate [120]. When coupled with DSC, DTI parameters were found to achieve an accuracy of up to $98 \%$ in one study [22]. In addition, Chen et al. propose a Bayesian-network-based decision support system to differentiate glioblastomas from solitary metastases using DTI, DSC, and FLAIR sequences [121].

\subsection{Neurite Orientation Dispersion and Density Imaging}

Just as DTI is an extension of DWI, providing more details about neuroanatomical microstructure, neurite orientation dispersion and density imaging (NODDI) takes it a step further. The morphology quantification of dendrites and axons, jointly known as neurites, has previously been restricted primarily to postmortem histology [122]. First introduced in 2012, NODDI is a practical diffusion MRI technique that can be used to estimate the intricacy of neurites in vivo on standard MRI scanners [123]. Neurite density and dispersion within the brain tissue can be mapped out and provide helpful information on brain connectivity [124]. For example, neurite density decreases as the brain ages [125], as well as in neurodegenerative disorders, such as multiple sclerosis [126], amyotrophic lateral sclerosis [127], and Alzheimer's disease [128]. The severity of disease progression can be assessed through the quantification of neurite density by NODDI analysis. In the same way that neurite density provides evidence of neurodegenerative disease, it can also provide data to illuminate other disease pathology, such as gliomas or brain metastasis [21].

NODDI simplifies the brain architecture into three compartments per voxel: the intracellular space, extracellular space, and cerebrospinal fluid. In this way, NODDI can provide more specific details on the microstructural changes of neurites than DTI analysis alone [123]. While DTI measures indices, such as FA and MD, to map out water diffusion within regions of interest, NODDI creates a compartment map by generating intracellular volume fraction (VIC), isotropic volume fraction (VISO), and extracellular volume fraction (VEC) [21].

In a small study of 15 patients ( 9 with confirmed glioblastoma and 6 with confirmed metastases), Kadota et al. found that VEC in the peritumoral signal change area was most useful in differentiating glioblastoma from metastases when compared with FA, MD, VIC, and VISO [21]. They determined that VEC provided $100 \%$ sensitivity and $83.3 \%$ specificity with a threshold value $\geq 0.48$. Inherent limitations of this study include the small sample size and not evaluating peritumoral T2-hyperintense regions.

In another recent study, Mao et al. compared the results of five diffusion-weighted MRI models in differentiating high-grade glioma from metastases [129]. This included a total of 42 previously untreated patients, 20 with confirmed high-grade glioma and 21 with confirmed metastases. They found that NODDI outperformed DTI and DWI in differentiating between high-grade glioma and metastases [130]. The single best parameter 
for differentiation between the two was found to be VISO. It is important to note that, unlike in the previous study mentioned, Mao et al. did not measure VEC [129].

\section{Metabolic Imaging}

\subsection{Magnetic Resonance Spectroscopy}

Magnetic resonance spectroscopy (MRS) is a unique modality from the other commonly used imaging techniques in that it provides data on multiple metabolic parameters. This modality has the ability to detect $\mathrm{N}$-acetylaspartate (NAA), creatine $(\mathrm{Cr})$, choline (Cho), glutamine, glutamate, myoinositol, lipid, lactate, and $\gamma$-aminobutyric acid (GABA). MRS is based primarily on the detection of signal arising from hydrogen nuclei; however, other nuclei can also arise with signal. These nuclei consist of a nonzero intrinsic magnetic moment, which can be manipulated by magnetic fields. These intrinsic moments arise from the spin of the nuclei, which is an effect of the quantum mechanical spin of the protons and neutrons of the nucleus [131]. From these spins, magnetization generates a magnetic resonance spectrum from these hydrogen protons. Frequencies are then detected by a radiofrequency coil placed near the brain. The electromagnetic force that is generated is proportional to the magnitude of magnetization, and this proportion allows the MRS to provide spectra of the signal source [131]. MRS is a magnetic resonance spectrum that graphically displays detected signals as a function of temporal frequencies (Figure 5).

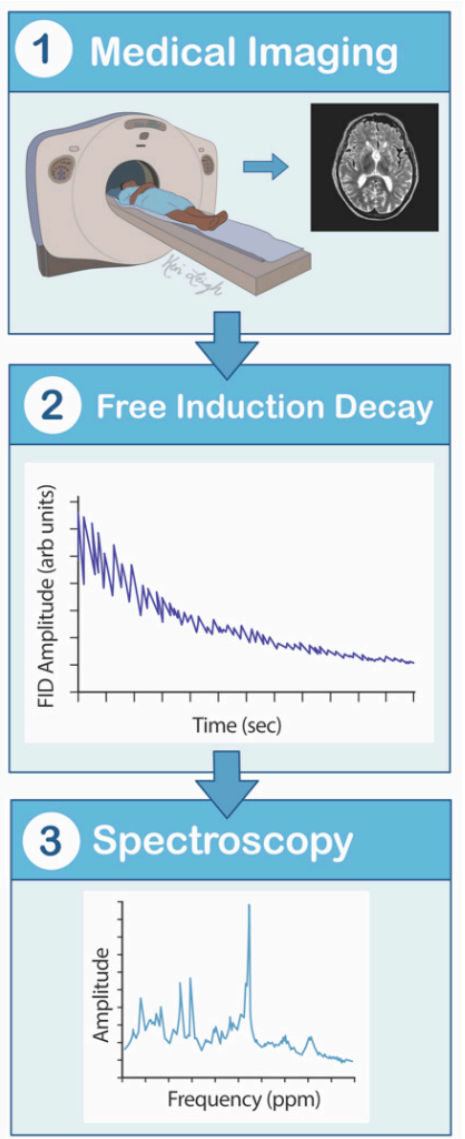

Figure 5. Magnetic resonance spectroscopy mechanism flowsheet. (1) The patient lies supine in the MRS scanner. (2) The hydrogen nuclei contain a nonzero intrinsic quantum mechanical spin of the protons and neutrons, which is manipulated by magnetic fields. Magnetization is applied, creating an observed nuclear magnetic resonance signal. Frequencies are then detected by a radiofrequency coil placed near the brain, creating a free induction decay. (3) The electromagnetic force that is generated is proportional to the magnitude of magnetization, and this proportion allows the MRS to provide spectra of the signal source. MRS is a magnetic resonance spectrum that graphically displays detected signals as a function of temporal frequencies. MRS—-magnetic resonance spectroscopy. 
Initial use of MRS for the detection and differentiation of brain tumors was largely limited as it showed great signal scatter and generally overlapped with normal brain tissue [132]. However, many improvements and developments have taken place, allowing radiologists to discern specific variables from these tumors used for identification. For identification purposes, prominent lipid signal indicates general cellular necrosis in both glioblastomas and metastases. However, new data show that MRS absolute lipid and macromolecular signals could help in differentiating glioblastoma from metastases. The LM13 class specifically was found to be a discriminant parameter being elevated with metastasis found to have an accuracy of $85 \%$ [23]. Lipid peak area ratios were also found to be 2.6 in glioblastoma when compared with 3.8 in metastasis when using short echo time $1 \mathrm{H}$ spectroscopy [133].

Peritumoral NAA/Cr, $\mathrm{Cho} / \mathrm{Cr}$, and Cho/NAA ratios also have evidence to support their use to differentiate glioblastoma from intracranial metastases at 3 Tesla [134,135]. Cho increases in the presence of increased cellular membrane turnover and proliferation; thus, it would theoretically be elevated in areas of tumor infiltration. This is true even in the absence of enhancement of $\mathrm{T} 2$ signal abnormality $[15,136]$. The highest Cho compounds are found in the peritumoral area of glioblastoma when compared with metastasis overall [120].

In addition, the presence of intratumoral $\mathrm{Cr}$ suggests glioma, whereas the absence of $\mathrm{Cr}$ indicates metastasis [137]. Choline/Cr greater than 2.48 is useful in detecting metastasis and glioblastoma when compared with $<2.48$, which would be indicative of cerebral infarction or radiation necrosis [138]. Intratumoral $\mathrm{Cho} / \mathrm{Cr}$ ratio is not as useful as peritumoral $\mathrm{Cho} / \mathrm{Cr}$ in differentiating the two diseases [139-144].

Deep learning protocols for MRS are being utilized to better characterize tumor disease. These protocols utilize complex nonlinear relationships and patterns found in both glioblastoma and metastases and identify a metabolic "footprint" instead of simply quantifying metabolite concentrations in the tumor [121,145].

\subsection{Positron Emission Tomography}

This imaging modality utilizes positron-emitting radiopharmaceuticals, such as (18) F-fluorodeoxyglucose (for imaging glucose metabolism) [146]. This imaging is derived from a process where decay occurs by the conversion of a proton into a neutron with positron emission. When the emitted proton unites with a nearby electron in an annihilation event, a pair of two photons ( $\gamma$-rays) are produced, each with an energy of 511 $\mathrm{keV}$ traveling in opposite directions. The $\gamma$-rays are detected by sensors on the positron emission tomography (PET) scanner. When both photons are detected in one coincidental event, an image is produced and is assumed to have occurred along the line of response (Figure 6) [147].

PET imaging using $\alpha$ [11C] methyl-1-tryptophan was found to differentiate glioblastoma from brain metastases and has an accuracy of $74 \%$. A kinetic tracer analysis separating tumoral tryptophan transport from unidirectional uptake rates using dynamic imaging was found to have a predictive value of $82 \%$. The combined accuracy of the two was $93 \%$ [24]. Metabolic uptake, however, is similar between glioblastoma and metastases but not different from any statistical significance [148]. One new advancement in PET imaging is using amino acids such as O- $\left(2-\left[{ }^{18} \mathrm{~F}\right]\right.$ fluroethyl)-L-tyrosine $\left({ }^{18} \mathrm{~F}\right.$-FET $)$ to allow for better characterizations of glioma. This achieves better characterization than PET imaging with glucose-based tracers, as glucose-based tracers have poorer contrast with the surrounding brain parenchyma. Amino acids have greater contrast as the neoplastic tissue uptake is clearly elevated since it has higher protein metabolism than the surrounding tissue. This allows for improved differentiation of glioma from metastasis [149]. 


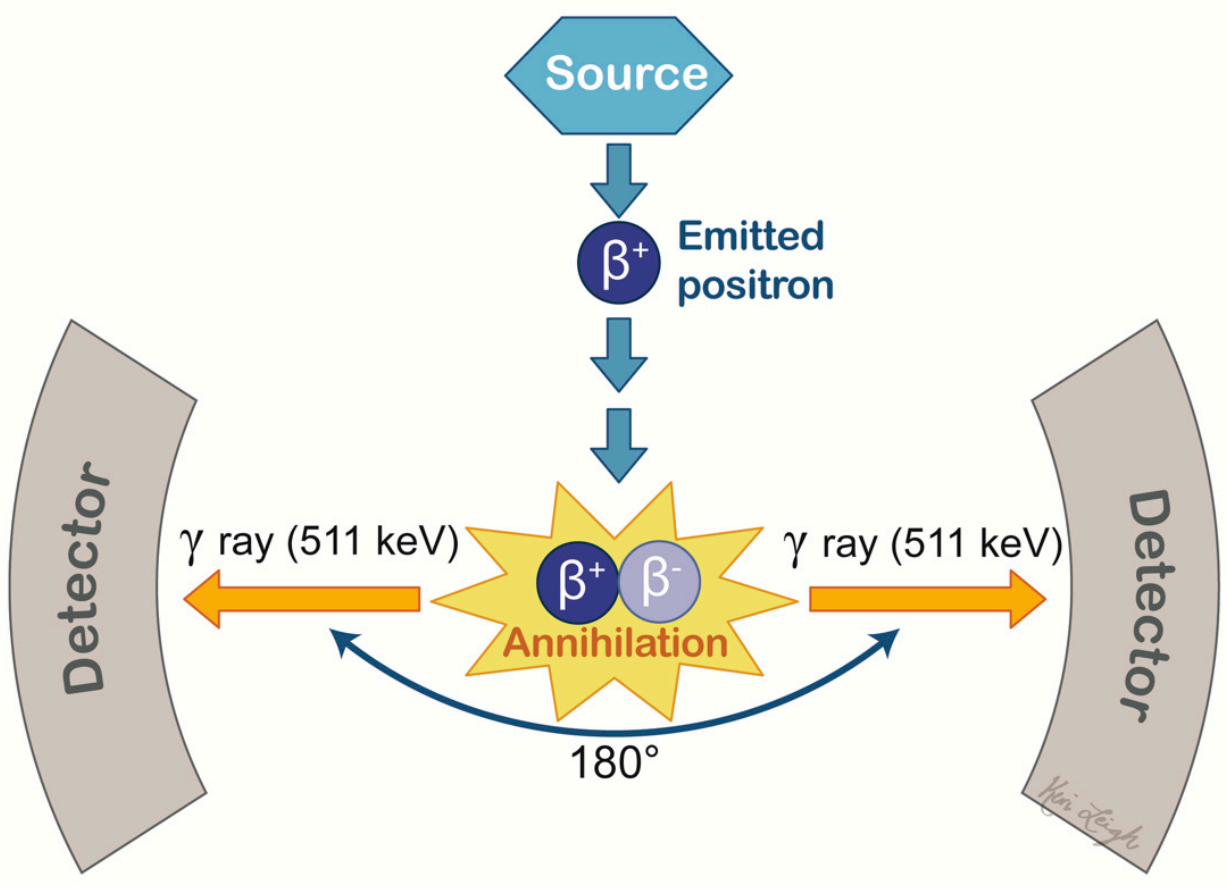

Figure 6. Positron emission tomography scan mechanism. Decay occurs by the conversion of a proton into a neutron with positron emission. When the emitted positron unites with a nearby electron in an annihilation event, a pair of two photons ( $\gamma$-rays) at $511 \mathrm{keV}$ are produced, each traveling in opposite directions. The $\gamma$-rays are detected by sensors on the PET scanner. When both photons are detected in one coincidental event, an image is produced and is assumed to have occurred along the line of response.

\subsection{Single-Photon Emission Computed Tomography}

Single-photon emission computed tomography (SPECT) has a mechanism of action similar to PET imaging; however, it requires a single physical collimator that absorbs a large fraction of the photons. Therefore, PET imaging is more sensitive than SPECT by two orders of magnitude [150].

When considering its usefulness for differentiating between glioblastomas and metastases, however, there is little evidence supporting the utility of this system. SPECT is useful for detecting bodywide metastases from glioblastoma [151].

\section{Phase Difference-Enhanced Imaging}

A new advanced imaging modality is able to enhance both paramagnetic and diamagnetic substances while being able to select which phases are enhanced. In addition, it can selectively enhance the contrast between the target tissue and the surrounding tissue. This is termed phase difference-enhanced imaging (PADRE). Doishita et al. developed color PADRE, which enables simultaneous visualization of myelin-rich structures and veins. They tested their new method on 11 patients. They found that the visibility of the superficial white matter was increased in metastases when compared with glioblastoma. Therefore, assessment of peritumoral areas with PADRE does appear to have the ability to assist with differentiation at this time [152].

\section{Radiomics-Based Machine Learning}

One innovative area of radiology is within machine learning, using computerized algorithms and protocols to achieve superior accuracy and sensitivity of imaging techniques. The advent of machine learning has resulted in its algorithms being increasingly used for a number of pathologies. These systems utilize support vector machines (SVMs) and multilayer perceptrons (MLPs) for the classification of brain tumors [121,153-156]. These are largely performed over several MR sequences. Radiomics analysis uses extracted 
data to include the patients' clinical information, tumor location, morphology, and wavelet features to a high degree of accuracy to assist with machine learning (Figure 7) [157-160].

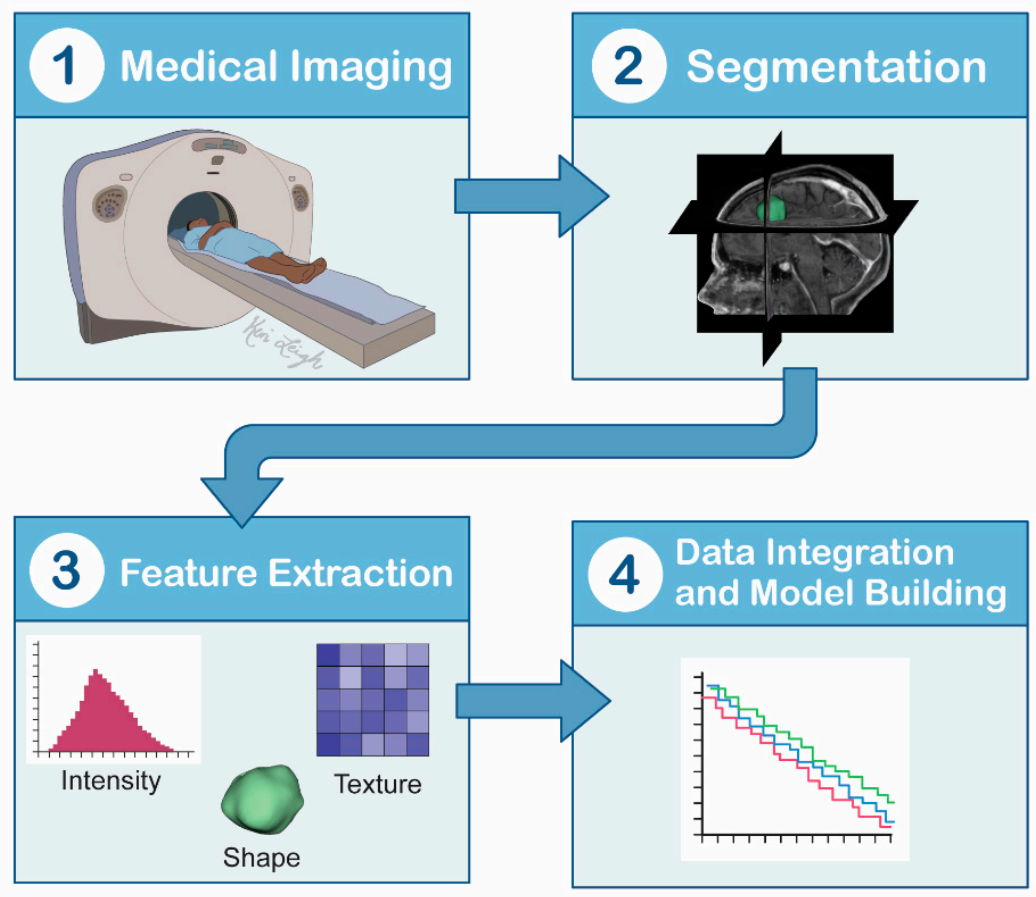

Figure 7. Radiomics and machine flow learning. (1) A medical image is generated using any one of the advanced imaging modalities or multiple, different modalities. $(2,3)$ Segmentation of the imaging is performed while also extracting feature data, such as intensity, texture, and shape. (4) This allows radiologists to build programs and algorithms to increase the sensitivity of imaging by creating systems that utilize support vector machines and multilayer perceptrons.

Swinburne et al. found that when using machine learning strategies with a variety of MR-specific sequences, including DWI, DCE, and DSC, machine learning capabilities can differentiate between glioblastomas and metastases with modest diagnostic accuracy. It has been found to provide up to $19 \%$ increase in diagnostic yield when added to human interpretation [161,162]. Qian et al. further found that one of their radiomic machine learning classifiers was superior in successfully differentiating glioblastoma from metastasis when compared with neuroradiologist interpretation in 412 patients [160]. Texture features are more significant than fractal-based features in differentiating the two diseases [163]. Threedimensional morphometric analysis has been used to provide up to $95.8 \%$ accuracy when using two three-dimensional shapes per tumor for classification. These three-dimensional features can be objectively derived from quantitative imaging [164].

Tsolaki et al. propose a machine learning algorithm that combines MRS data with DSC in the peritumoral area, leading to an accuracy of up to 98\% [25]. Yang et al. developed a computerized system using a semiautomatic segmentation method for DTI imaging and two-dimensional morphological feature extraction and selection and a pattern recognition module for tumor classification. This achieved an accuracy of $97.9 \%$ [26]. Therefore, machine learning algorithms have great potential to become optimized and improve diagnostic accuracy in the future. This is especially true when they incorporate multiple, different advanced imaging modalities that could potentially be used for differentiation (Table 1).

Additionally, molecular characterization of these tumors has advanced considerably in the past decade. There is a distinction between IDH1 mutant tumors and EGFR mutant glioblastomas. While tumors with IDH1 mutations often have a more favorable prognosis, EGFR mutations suggest more aggressive tumors. IDH1 has been found to create a hypermethylator phenotype, while EGFR mutations act as functional driver genes $[165,166]$. 
Rathore et al. found that MRI could be successfully used to differentiate between these two mutations using radiomic MRI signatures. They were able to differentiate a total of three different phenotypic subtypes by MRI [167]. Perfusion signatures have also been found to be accurate in detecting EGFRvIII status [168].

\section{Conclusions}

Conventional MRI is standard for initial workup of intracranial tumors; however, it remains difficult to differentiate the two pathologies when using conventional MRI as the sole imaging modality. Optimal parameters for the use of $\mathrm{rCBV}$ in DSC is becoming much more delineated. New advancements have been made with diffusion imaging techniques to include DTI, in addition to NODDI, which appears to be promising for accurate differentiation in the future. Finally, multiple algorithms for radiomics and machine-based learning programs are being developed, often incorporating multiple advanced imaging modalities to achieve high levels of accuracy.

Author Contributions: Writing-original draft preparation, A.-J.F.; writing-review and editing, C.-C.H., N.P., and B.M.; visualization, K.J.; project administration, M.A.; conceptualization and supervision, J.G. All authors have read and agreed to the published version of the manuscript.

Funding: This research received no external funding.

Institutional Review Board Statement: Not applicable.

Informed Consent Statement: Not applicable.

Data Availability Statement: Not applicable.

Conflicts of Interest: The authors declare no conflict of interest.

\section{References}

1. Ostrom, Q.T.; Gittleman, H.; Liao, P.; Rouse, C.; Chen, Y.; Dowling, J.; Wolinsky, Y.; Kruchko, C.; Barnholtz-Sloan, J. CBTRUS Statistical Report: Primary brain and central nervous system tumors diagnosed in the United States in 2007-2011. Neuro Oncol. 2014, 16, 1-63.

2. Fox, B.D.; Cheung, V.J.; Patel, A.J.; Suki, D.; Rao, G. Epidemiology of Metastatic Brain Tumors. Neurosurg. Clin. N. Am. 2011, 22, 1-6. [CrossRef]

3. Patchell, R.A.; Tibbs, P.A.; Walsh, J.W.; Dempsey, R.J.; Maruyama, Y.; Kryscio, R.J.; Markesbery, W.R.; Macdonald, J.S.; Young, B. A randomized trial of surgery in the treatment of single metastases to the brain. N. Engl. J. Med. 1990, 322, 494-500.

4. Gavrilovic, I.T.; Posner, J.B. Brain metastases: Epidemiology and pathophysiology. Neurooncology 2005, 75, 5-14. [CrossRef]

5. Lee, E.J.; Ahn, K.J.; Lee, E.K.; Lee, Y.S.; Kim, D.B. Potential role of advanced MRI techniques for the peritumoural region in differentiating glioblastoma multiforme and solitary metastatic lesions. Clin. Radiol. 2013, 68, 689-697.

6. Weller, M.; van den Bent, M.; Hopkins, K.; Tonn, J.C.; Stupp, R.; Falini, A.; Cohen-Jonathan-Moyal, E.; Frappaz, D.; Henriksson, R.; Balana, C.; et al. EANO Guideline for the diagnosis and treatment of anaplastic gliomas and glioblastoma. Lancet Oncol. 2014, 15, 395-403. [CrossRef]

7. Lin, X.; DeAngelis, L.M. Treatment of brain metastases. J. Clin. Oncol. 2015, 33, 3475-3484. [CrossRef] [PubMed]

8. Oh, J.; Cha, S.; Aiken, A.H.; Han, E.T.; Crane, J.C.; Stainsby, J.A.; Wright, G.A.; Dillon, W.P.; Nelson, S.J. Quantitative apparent diffusion coefficients and T2 relaxation times in characterizing contrast enhancing brain tumors and regions of peritumoral edema. J. Magn. Reson. Imaging 2005, 21, 701-708. [PubMed]

9. Lu, S.; Ahn, D.; Johnson, G.; Cha, S. Peritumoral diffusion tensor imaging of high-grade gliomas and metastatic brain tumors. Am. J. Neuroradiol. 2003, 24, 937-941. [PubMed]

10. Tang, Y.M.; Ngai, S.; Stuckey, S. The solitary enhancing cerebral lesion: Can FLAIR aid the differentiation between glioma and metastasis. Am. J. Neuroradiol. 2006, 27, 609-611. [PubMed]

11. Chiang, I.C.; Kuo, Y.T.; Lu, C.Y.; Yeung, K.W.; Lin, W.C.; Sheu, F.O.; Liu, G.C. Distinction between high-grade gliomas and solitary metastases using peritumoral 3-T magnetic resonance spectroscopy, diffusion, and perfusion imagings. Neuroradiology 2004, 46, 619-627. [CrossRef] [PubMed]

12. Bulakbasi, N.; Kocaoglu, M.; Ors, F.; Tayfun, C.; Ucoz, T. Combination of single-voxel proton MR spectroscopy and apparent diffusion coefficient calculation in the evaluation of common brain tumors. Am. J. Neuroradiol. 2003, 24, 225-233. [PubMed]

13. Law, M.; Cha, S.; Knopp, E.A.; Johnson, G.; Arnett, J.; Litt, A.W. High-grade gliomas and solitary metastases: Differentiation by using perfusion and proton spectroscopic MR imaging. Radiology 2002, 222, 715-721. [CrossRef]

14. Mukundan, S.; Holder, C.; Olson, J.J. Neuroradiological assessment of newly diagnosed glioblastoma. J. Neurooncol. 2008, 89, 259-269. [CrossRef] 
15. Cha, S. Neuroimaging in Neuro-Oncology. Neurotherapeutics 2009, 6, 465-477. [CrossRef]

16. Magnetic Resonance Imaging (MRI). Available online: https://www.nibib.nih.gov/science-education/science-topics/magneticresonance-imaging-mri (accessed on 12 April 2021).

17. Stuckey, S.L.; Wijedeera, R. Multicentric/multifocal cerebral lesions: Can fluid-attenuated inversion recovery aid the differentiation between glioma and metastases? J. Med. Imaging Radiat. Oncol. 2008, 52, 134-139. [CrossRef]

18. Maurer, M.H.; Synowitz, M.; Badakshi, H.; Lohkamp, L.N.; Wüstefeld, J.; Schäfer, M.L.; Wiener, E. Glioblastoma multiforme versus solitary supratentorial brain metastasis: Differentiation based on morphology and magnetic resonance signal characteristics. RoFo Fortschritte auf dem Gebiet der Rontgenstrahlen und der Bildgeb 2013, 185, 235-240. [CrossRef] [PubMed]

19. Suh, C.H.; Kim, H.S.; Jung, S.C.; Choi, C.G.; Kim, S.J. MRI findings in tumefactive demyelinating lesions: A systematic review and meta-analysis. Am. J. Neuroradiol. 2018, 39, 1643-1649. [CrossRef] [PubMed]

20. Suh, C.H.; Kim, H.S.; Jung, S.C.; Kim, S.J. Diffusion-Weighted Imaging and Diffusion Tensor Imaging for Differentiating HighGrade Glioma from Solitary Brain Metastasis: A Systematic Review and Meta-Analysis. AJNR. Am. J. Neuroradiol. 2018, 39, 1208-1214. [CrossRef] [PubMed]

21. Kadota, Y.; Hirai, T.; Azuma, M.; Hattori, Y.; Khant, Z.A.; Hori, M.; Saito, K.; Yokogami, K.; Takeshima, H. Differentiation between glioblastoma and solitary brain metastasis using neurite orientation dispersion and density imaging. J. Neuroradiol. 2020, 47, 197-202. [CrossRef] [PubMed]

22. Bauer, A.H.; Erly, W.; Moser, F.G.; Maya, M.; Nael, K. Differentiation of solitary brain metastasis from glioblastoma multiforme: A predictive multiparametric approach using combined MR diffusion and perfusion. Neuroradiology 2015, 57, 697-703. [CrossRef] [PubMed]

23. Crisi, G.; Orsingher, L.; Filice, S. Lipid and macromolecules quantitation in differentiating glioblastoma from solitary metastasis: A short-echo time single-voxel magnetic resonance spectroscopy study at 3 T. J. Comput. Assist. Tomogr. 2013, 37, $265-271$. [CrossRef] [PubMed]

24. Kamson, D.O.; Mittal, S.; Buth, A.; Muzik, O.; Kupsky, W.J.; Robinette, N.L.; Barger, G.R.; Juhász, C. Differentiation of glioblastomas from metastatic brain tumors by tryptophan uptake and kinetic analysis: A positron emission tomographic study with magnetic resonance imaging comparison. Mol. Imaging 2013, 12, 327-337. [CrossRef] [PubMed]

25. Meier, R.; Pahud de Mortanges, A.; Wiest, R.; Knecht, U. Exploratory Analysis of Qualitative MR Imaging Features for the Differentiation of Glioblastoma and Brain Metastases. Front. Oncol. 2020, 10, 2576. [CrossRef]

26. Yang, G.; Jones, T.L.; Barrick, T.R.; Howe, F.A. Discrimination between glioblastoma multiforme and solitary metastasis using morphological features derived from the $\mathrm{p}$ : $\mathrm{Q}$ tensor decomposition of diffusion tensor imaging. NMR Biomed. 2014, 27, 1103-1111. [CrossRef]

27. Wahsner, J.; Gale, E.M.; Rodríguez-Rodríguez, A.; Caravan, P. Chemistry of MRI contrast agents: Current challenges and new frontiers. Chem. Rev. 2019, 119, 957-1057. [CrossRef]

28. Runge, V.M. Critical questions regarding gadolinium deposition in the brain and body after injections of the gadolinium-based contrast agents, safety, and clinical recommendations in consideration of the EMA's pharmacovigilance and risk assessment committee recommendation for suspension of the marketing authorizations for 4 linear agents. Investig. Radiol. 2017, 52, 317-323.

29. Wang, S.; Kim, S.; Chawla, S.; Wolf, R.L.; Knipp, D.E.; Vossough, A.; O’Rourke, D.M.; Judy, K.D.; Poptani, H.; Melhem, E.R. Differentiation between glioblastomas, solitary brain metastases, and primary cerebral lymphomas using diffusion tensor and dynamic susceptibility contrast-enhanced MR imaging. Am. J. Neuroradiol. 2011, 32, 507-514. [CrossRef]

30. Van Dijken, B.R.J.; van Laar, P.J.; Smits, M.; Dankbaar, J.W.; Enting, R.H.; van der Hoorn, A. Perfusion MRI in treatment evaluation of glioblastomas: Clinical relevance of current and future techniques. J. Magn. Reson. Imaging 2019, 49, 11-22. [CrossRef]

31. Neska-Matuszewska, M.; Bladowska, J.; Sąsiadek, M.; Zimny, A. Differentiation of glioblastoma multiforme, metastases and primary central nervous system lymphomas using multiparametric perfusion and diffusion MR imaging of a tumor core and a peritumoral zone-Searching for a practical approach. PLoS ONE 2018, 13, e0191341.

32. Dickerson, E.; Srinivasan, A. Multicenter Survey of Current Practice Patterns in Perfusion MRI in Neuroradiology: Why, When, and How Is It Performed? Am. J. Roentgenol. 2016, 207, 406-410. [CrossRef]

33. Essig, M.; Shiroishi, M.S.; Nguyen, T.B.; Saake, M.; Provenzale, J.M.; Enterline, D.; Anzalone, N.; Dörfler, A.; Rovira, À.; Wintermark, M.; et al. Perfusion MRI: The five most frequently asked technical questions. Am. J. Roentgenol. 2013, $200,24-34$. [CrossRef]

34. Suh, C.H.; Kim, H.S.; Jung, S.C.; Choi, C.G.; Kim, S.J. Perfusion MRI as a diagnostic biomarker for differentiating glioma from brain metastasis: A systematic review and meta-analysis. Eur. Radiol. 2018, 28, 3819-3831. [CrossRef] [PubMed]

35. Chaudhry, I.H.; O'Donovan, D.G.; Brenchley, P.E.C.; Reid, H.; Roberts, I.S.D. Vascular endothelial growth factor expression correlates with tumour grade and vascularity in gliomas. Histopathology 2001, 39, 409-415. [CrossRef] [PubMed]

36. Askaner, K.; Rydelius, A.; Engelholm, S.; Knutsson, L.; Lätt, J.; Abul-Kasim, K.; Sundgren, P.C. Differentiation between glioblastomas and brain metastases and regarding their primary site of malignancy using dynamic susceptibility contrast MRI at 3T. J. Neuroradiol. 2019, 46, 367-372. [CrossRef]

37. Wetzel, S.G.; Cha, S.; Johnson, G.; Lee, P.; Law, M.; Kasow, D.L.; Pierce, S.D.; Xue, X. Relative cerebral blood volume measurements in intracranial mass lesions: Interobserver and intraobserver reproducibility study. Radiology 2002, 224, 797-803. [CrossRef] [PubMed] 
38. Blasel, S.; Jurcoane, A.; Franz, K.; Morawe, G.; Pellikan, S.; Hattingen, E. Elevated peritumoural rCBV values as a mean to differentiate metastases from high-grade gliomas. Acta Neurochir. 2010, 152, 1893-1899. [CrossRef]

39. Claes, A.; Idema, A.J.; Wesseling, P. Diffuse glioma growth: A guerilla war. Acta Neuropathol. 2007, 114, 443-458. [CrossRef]

40. Blasel, S.; Franz, K.; Mittelbronn, M.; Morawe, G.; Jurcoane, A.; Pellikan, S.; Zanella, F.; Hattingen, E. The striate sign: Peritumoural perfusion pattern of infiltrative primary and recurrent gliomas. Neurosurg. Rev. 2010, 33, 193-204. [CrossRef]

41. Cha, S.; Knopp, E.A.; Johnson, G.; Wetzel, S.G.; Litt, A.W.; Zagzag, D. Intracranial mass lesions: Dynamic contrast-enhanced susceptibility-weighted echo-planar perfusion MR imaging. Radiology 2002, 223, 11-29. [CrossRef]

42. Machein, M.R.; Plate, K.H. VEGF in brain tumors. J. Neurooncol. 2000, 50, 109-120. [CrossRef] [PubMed]

43. Hakyemez, B.; Erdogan, C.; Bolca, N.; Yildirim, N.; Gokalp, G.; Parlak, M. Evaluation of different cerebral mass lesions by perfusion-weighted MR imaging. J. Magn. Reson. Imaging 2006, 24, 817-824. [CrossRef] [PubMed]

44. Server, A.; Orheim, T.E.D.; Graff, B.A.; Josefsen, R.; Kumar, T.; Nakstad, P.H. Diagnostic examination performance by using microvascular leakage, cerebral blood volume, and blood flow derived from 3-T dynamic susceptibility-weighted contrastenhanced perfusion MR imaging in the differentiation of glioblastoma multiforme and brain metastasis. Neuroradiology 2011, 53, 319-330. [PubMed]

45. Zhang, M.; Olsson, Y. Hematogenous metastases of the human brain-Characteristics of peritumoral brain changes: A review. J. Neurooncol. 1997, 35, 81-89. [CrossRef] [PubMed]

46. Park, J.E.; Kim, H.S.; Lee, J.; Cheong, E.N.; Shin, I.; Ahn, S.S.; Shim, W.H. Deep-learned time-signal intensity pattern analysis using an autoencoder captures magnetic resonance perfusion heterogeneity for brain tumor differentiation. Sci. Rep. 2020, 10, 21485. [CrossRef] [PubMed]

47. Coban, G.; Mohan, S.; Kural, F.; Wang, S.; O’Rourke, D.M.; Poptani, H. Prognostic Value of Dynamic Susceptibility ContrastEnhanced and Diffusion-Weighted MR Imaging in Patients with Glioblastomas. Am. J. Neuroradiol. 2015, 36, $1247-1252$. [CrossRef]

48. Burth, S.; Kickingereder, P.; Eidel, O.; Tichy, D.; Bonekamp, D.; Weberling, L.; Wick, A.; Löw, S.; Hertenstein, A.; Nowosielski, M.; et al. Clinical parameters outweigh diffusion- and perfusion-derived MRI parameters in predicting survival in newly diagnosed glioblastoma. Neuro Oncol. 2016, 18, 1673-1679. [CrossRef] [PubMed]

49. Cha, S.; Lupo, J.M.; Chen, M.H.; Lamborn, K.R.; McDermott, M.W.; Berger, M.S.; Nelson, S.J.; Dillon, W.P. Differentiation of glioblastoma multiforme and single brain metastasis by peak height and percentage of signal intensity recovery derived from dynamic susceptibility-weighted contrast-enhanced perfusion MR imaging. Am. J. Neuroradiol. 2007, 28, 1078-1084. [CrossRef] [PubMed]

50. Cindil, E.; Sendur, H.N.; Cerit, M.N.; Dag, N.; Erdogan, N.; Celebi, F.E.; Oner, Y.; Tali, T. Validation of combined use of DWI and percentage signal recovery-optimized protocol of DSC-MRI in differentiation of high-grade glioma, metastasis, and lymphoma. Neuroradiology 2021, 63, 331-342. [CrossRef]

51. Hu, L.S.; Baxter, L.C.; Smith, K.A.; Feuerstein, B.G.; Karis, J.P.; Eschbacher, J.M.; Coons, S.W.; Nakaji, P.; Yeh, R.F.; Debbins, J.; et al. Relative cerebral blood volume values to differentiate high-grade glioma recurrence from posttreatment radiation effect: Direct correlation between image-guided tissue histopathology and localized dynamic susceptibility-weighted contrast-enhanced perfusion MR imaging measurements. Am. J. Neuroradiol. 2009, 30, 552-558.

52. Wintermark, M.; Sesay, M.; Barbier, E.; Borbély, K.; Dillon, W.P.; Eastwood, J.D.; Glenn, T.C.; Grandin, C.B.; Pedraza, S.; Soustiel, J.F.; et al. Comparative Overview of Brain Perfusion Imaging Techniques. Stroke 2005, 36, 83-99. [CrossRef]

53. Keston, P.; Murray, A.D.; Jackson, A. Cerebral perfusion imaging using contrast-enhanced MRI. Clin. Radiol. 2003, 58, 505-513. [CrossRef]

54. Carroll, T.; Haughton, V.; Rowley, H.; Cordes, D. Confounding effect of large vessels on MR perfusion images analyzed with independent component analysis. Am. J. Neuroradiol. 2002, 23, 1007-1012. [PubMed]

55. Reber, P.J.; Wong, E.C.; Buxton, R.B.; Frank, L.R. Correction of off resonance-related distortion in echo-planar imaging using EPI-based field maps. Magn. Reson. Med. 1998, 39, 328-330. [CrossRef]

56. Halshtok Neiman, O.; Sadetzki, S.; Chetrit, A.; Raskin, S.; Yaniv, G.; Hoffmann, C. Perfusion-weighted imaging of peritumoral edema can aid in the differential diagnosis of glioblastoma multiforme versus brain metastasis. Isr. Med. Assoc. J. 2013, 15, 103-105. [PubMed]

57. Welker, K.; Boxerman, J.; Kalnin, A.; Kaufmann, T.; Shiroishi, M.; Wintermark, M. ASFNR recommendations for clinical performance of MR dynamic susceptibility contrast perfusion imaging of the brain. Am. J. Neuroradiol. 2015, 36, 41-51. [CrossRef] [PubMed]

58. Akella, N.S.; Twieg, D.B.; Mikkelsen, T.; Hochberg, F.H.; Grossman, S.; Cloud, G.A.; Nabors, L.B. Assessment of brain tumor angiogenesis inhibitors using perfusion magnetic resonance imaging: Quality and analysis results of a phase I trial. J. Magn. Reson. Imaging 2004, 20, 913-922. [CrossRef]

59. Larsson, H.B.W.; Stubgaard, M.; Frederiksen, J.L.; Jensen, M.; Henriksen, O.; Paulson, O.B. Quantitation of blood-brain barrier defect by magnetic resonance imaging and gadolinium-DTPA in patients with multiple sclerosis and brain tumors. Magn. Reson. Med. 1990, 16, 117-131. [CrossRef]

60. Sourbron, S.P.; Buckley, D.L. Classic models for dynamic contrast-enhanced MRI. NMR Biomed. 2013, 26, 1004-1027. [CrossRef]

61. Erlemann, R.; Reiser, M.F.; Peters, P.E.; Vasallo, P.; Nommensen, B.; Kusnierz-Glaz, C.R.; Ritter, J.; Roessner, A. Musculoskeletal neoplasms: Static and dynamic Gd-DTPA-enhanced MR imaging. Radiology 1989, 171, 767-773. [CrossRef] 
62. Jahng, G.H.; Li, K.L.; Ostergaard, L.; Calamante, F. Perfusion magnetic resonance imaging: A comprehensive update on principles and techniques. Korean J. Radiol. 2014, 15, 554-577. [CrossRef] [PubMed]

63. Tofts, P.S.; Brix, G.; Buckley, D.L.; Evelhoch, J.L.; Henderson, E.; Knopp, M.V.; Larsson, H.B.W.; Lee, T.Y.; Mayr, N.A.; Parker, G.J.M.; et al. Estimating kinetic parameters from dynamic contrast-enhanced T1- weighted MRI of a diffusable tracer: Standardized quantities and symbols. J. Magn. Reson. Imaging 1999, 10, 223-232. [CrossRef]

64. Jackson, A.; Jayson, G.C.; Li, K.L.; Zhu, X.P.; Checkley, D.R.; Tessier, J.J.L.; Waterton, J.C. Reproducibility of quantitative dynamic contrast-enhanced MRI in newly presenting glioma. Br. J. Radiol. 2003, 76, 153-162. [CrossRef] [PubMed]

65. Jung, B.C.; Arevalo-Perez, J.; Lyo, J.K.; Holodny, A.I.; Karimi, S.; Young, R.J.; Peck, K.K. Comparison of Glioblastomas and Brain Metastases using Dynamic Contrast-Enhanced Perfusion MRI. J. Neuroimaging 2016, 26, 240-246. [CrossRef]

66. Zhao, J.; Yang, Z.; Luo, B.; Yang, J.; Chu, J. Quantitative Evaluation of Diffusion and Dynamic Contrast-Enhanced MR in Tumor Parenchyma and Peritumoral Area for Distinction of Brain Tumors. PLoS ONE 2015, 10, e0138573. [CrossRef]

67. Williams, D.S.; Detre, J.A.; Leigh, J.S.; Koretsky, A.P. Magnetic resonance imaging of perfusion using spin inversion of arterial water. Proc. Natl. Acad. Sci. USA 1992, 89, 212-216. [CrossRef] [PubMed]

68. White, C.M.; Pope, W.B.; Zaw, T.; Qiao, J.; Naeini, K.M.; Lai, A.; Nghiemphu, P.L.; Wang, J.J.; Cloughesy, T.F.; Ellingson, B.M. Regional and Voxel-Wise Comparisons of Blood Flow Measurements Between Dynamic Susceptibility Contrast Magnetic Resonance Imaging (DSC-MRI) and Arterial Spin Labeling (ASL) in Brain Tumors. J. Neuroimaging 2014, 24, 23-30. [CrossRef]

69. Schmid, S.; Petersen, E.T.; Van Osch, M.J.P. Insight into the labeling mechanism of acceleration selective arterial spin labeling. Magn. Reson. Mater. Phys. Biol. Med. 2017, 30, 165-174. [CrossRef]

70. Lehmann, P.; Monet, P.; De Marco, G.; Saliou, G.; Perrin, M.; Stoquart-Elsankari, S.; Bruniau, A.; Vallée, J.N. A comparative study of perfusion measurement in brain tumours at 3 tesla MR: Arterial spin labeling versus dynamic susceptibility contrast-enhanced MRI. Eur. Neurol. 2010, 64, 21-26. [CrossRef]

71. Noguchi, T.; Yoshiura, T.; Hiwatashi, A.; Togao, O.; Yamashita, K.; Nagao, E.; Shono, T.; Mizoguchi, M.; Nagata, S.; Sasaki, T.; et al. Perfusion imaging of brain tumors using arterial spin-labeling: Correlation with histopathologic vascular density. Am. J. Neuroradiol. 2008, 29, 688-693. [CrossRef]

72. Järnum, H.; Steffensen, E.G.; Knutsson, L.; Fründ, E.T.; Simonsen, C.W.; Lundbye-Christensen, S.; Shankaranarayanan, A.; Alsop, D.C.; Jensen, F.T.; Larsson, E.M. Perfusion MRI of brain tumours: A comparative study of pseudo-continuous arterial spin labelling and dynamic susceptibility contrast imaging. Neuroradiology 2010, 52, 307-317. [CrossRef] [PubMed]

73. Warmuth, C.; Günther, M.; Zimmer, C. Quantification of blood flow in brain tumors: Comparison of arterial spin labeling and dynamic susceptibility-weighted contrast-enhanced MR imaging. Radiology 2003, 228, 523-532. [CrossRef] [PubMed]

74. Buck, J.; Larkin, J.R.; Simard, M.A.; Khrapitchev, A.A.; Chappell, M.A.; Sibson, N.R. Sensitivity of multiphase pseudocontinuous arterial spin labelling (MP pCASL) magnetic resonance imaging for measuring brain and tumour blood flow in mice. Contrast Media Mol. Imaging 2018, 2018, 4580919. [CrossRef]

75. Gryazov, A.B.; Medvedovska, Y.V.; Gryazov, A.A. Differential diagnostics of a radionecrosis and local tumoral recurrence according to arterial spin labelling after radiosurgery treatment of malignant gliomas of a brain. Wiad. Lek. 2020, 73, 2160-2164. [CrossRef] [PubMed]

76. Di, N.; Cheng, W.; Chen, H.; Zhai, F.; Liu, Y.; Mu, X.; Chu, Z.; Lu, N.; Liu, X.; Wang, B. Utility of arterial spin labelling MRI for discriminating atypical high-grade glioma from primary central nervous system lymphoma. Clin. Radiol. 2019, 74, 1-9. [CrossRef] [PubMed]

77. You, S.H.; Yun, T.J.; Choi, H.J.; Yoo, R.E.; Kang, K.M.; Choi, S.H.; Kim, J.H.; Sohn, C.H. Differentiation between primary CNS lymphoma and glioblastoma: Qualitative and quantitative analysis using arterial spin labeling MR imaging. Eur. Radiol. 2018, 28, 3801-3810. [CrossRef]

78. Lin, L.; Xue, Y.; Duan, Q.; Sun, B.; Lin, H.; Huang, X.; Chen, X. The role of cerebral blood flow gradient in peritumoral edema for differentiation of glioblastomas from solitary metastatic lesions. Oncotarget 2016, 7, 69051-69059. [CrossRef]

79. Abdel Razek, A.A.K.; Talaat, M.; El-Serougy, L.; Abdelsalam, M.; Gaballa, G. Differentiating Glioblastomas from Solitary Brain Metastases Using Arterial Spin Labeling Perfusion- and Diffusion Tensor Imaging-Derived Metrics. World Neurosurg. 2019, 127, 593-598. [CrossRef] [PubMed]

80. Ganbold, M.; Harada, M.; Khashbat, D.; Abe, T.; Kageji, T.; Nagahiro, S. Differences in high-intensity signal volume between arterial spin labeling and contrast-enhanced T1-weighted imaging may be useful for differentiating glioblastoma from brain metastasis. J. Med. Investig. 2017, 64, 58-63. [CrossRef]

81. Le Bihan, D. Diffusion MRI: What water tells us about the brain. EMBO Mol. Med. 2014, 6, 569-573. [CrossRef]

82. Tournier, J.D.; Mori, S.; Leemans, A. Diffusion tensor imaging and beyond. Magn. Reson. Med. 2011, 65, 1532-1556. [CrossRef]

83. Yamasaki, F.; Kurisu, K.; Satoh, K.; Arita, K.; Sugiyama, K.; Ohtaki, M.; Takaba, J.; Tominaga, A.; Hanaya, R.; Yoshioka, H.; et al. Apparent diffusion coefficient of human brain tumors at MR imaging. Radiology 2005, 235, 985-991. [CrossRef]

84. Baliyan, V.; Das, C.J.; Sharma, R.; Gupta, A.K. Diffusion weighted imaging: Technique and applications. World J. Radiol. 2016, 8 , 785. [CrossRef] [PubMed]

85. Serai, S.D. Basics of magnetic resonance imaging and quantitative parameters T1, T2, T2*, T1rho and diffusion-weighted imaging. Pediatr. Radiol. 2021. [CrossRef]

86. Mannelli, L.; Nougaret, S.; Vargas, H.A.; Do, R.K.G. Advances in Diffusion-Weighted Imaging. Radiol. Clin. N. Am. 2015, 53, 569-581. [PubMed] 
87. Calli, C.; Kitis, O.; Yunten, N.; Yurtseven, T.; Islekel, S.; Akalin, T. Perfusion and diffusion MR imaging in enhancing malignant cerebral tumors. Eur. J. Radiol. 2006, 58, 394-403. [CrossRef] [PubMed]

88. Kono, K.; Inoue, Y.; Nakayama, K.; Shakudo, M.; Morino, M.; Ohata, K.; Wakasa, K.; Yamada, R. The role of diffusion-weighted imaging in patients with brain tumors. Am. J. Neuroradiol. 2001, 22, 1081-1088.

89. Krabbe, K.; Gideon, P.; Wagn, P.; Hansen, U.; Thomsen, C.; Madsen, F. MR diffusion imaging of human intracranial tumours. Neuroradiology 1997, 39, 483-489. [CrossRef]

90. Stadnik, T.W.; Chaskis, C.; Michotte, A.; Shabana, W.M.; van Rompaev, K.; Luypaert, R.; Budinsky, L.; Jellus, V.; Osteaux, M. Diffusion-weighted MR imaging of intracerebral masses: Comparison with conventional MR imaging and histologic findings. Am. J. Neuroradiol. 2001, 22, 969-976.

91. Tepe, M.; Saylisoy, S.; Toprak, U.; Inan, I. The Potential Role of Peritumoral Apparent Diffusion Coefficient Evaluation in Differentiating Glioblastoma and Solitary Metastatic Lesions of the Brain. Curr. Med. Imaging 2021, 17. [CrossRef]

92. Zhang, G.; Chen, X.; Zhang, S.; Ruan, X.; Gao, C.; Liu, Z.; Wei, X. Discrimination Between Solitary Brain Metastasis and Glioblastoma Multiforme by Using ADC-Based Texture Analysis: A Comparison of Two Different ROI Placements. Acad. Radiol. 2019, 26, 1466-1472. [CrossRef]

93. Pavlisa, G.; Rados, M.; Pavlisa, G.; Pavic, L.; Potocki, K.; Mayer, D. The differences of water diffusion between brain tissue infiltrated by tumor and peritumoral vasogenic edema. Clin. Imaging 2009, 33, 96-101. [CrossRef] [PubMed]

94. Rollin, N.; Guyotat, J.; Streichenberger, N.; Honnorat, J.; Tran Minh, V.A.; Cotton, F. Clinical relevance of diffusion and perfusion magnetic resonance imaging in assessing intra-axial brain tumors. Neuroradiology 2006, 48, 150-159. [CrossRef] [PubMed]

95. Lee, E.J.; TerBrugge, K.; Mikulis, D.; Choi, D.S.; Bae, J.M.; Lee, S.K.; Moon, S.Y. Diagnostic value of peritumoral minimum apparent diffusion coefficient for differentiation of glioblastoma multiforme from solitary metastatic lesions. Am. J. Roentgenol. 2011, 196, 71-76. [CrossRef] [PubMed]

96. Provenzale, J.M.; Engelter, S.T.; Petrella, J.R.; Smith, J.S.; MacFall, J.R. Use of MR exponential diffusion-weighted images to eradicate T2 "shine- through" effect. Am. J. Roentgenol. 1999, 172, 537-539. [CrossRef]

97. Hakyemez, B.; Erdogan, C.; Gokalp, G.; Dusak, A.; Parlak, M. Solitary metastases and high-grade gliomas: Radiological differentiation by morphometric analysis and perfusion-weighted MRI. Clin. Radiol. 2010, 65, 15-20. [CrossRef] [PubMed]

98. Basser, P.J.; Mattiello, J.; LeBihan, D. MR diffusion tensor spectroscopy and imaging. Biophys. J. 1994, 66, 259-267. [CrossRef]

99. Beaulieu, C. The basis of anisotropic water diffusion in the nervous system-A technical review. NMR Biomed. 2002, 15, 435-455. [CrossRef]

100. Soares, J.M.; Marques, P.; Alves, V.; Sousa, N. A hitchhiker's guide to diffusion tensor imaging. Front. Neurosci. $2013,7,31$. [CrossRef]

101. Hagmann, P.; Jonasson, L.; Maeder, P.; Thiran, J.P.; Van Wedeen, J.; Meuli, R. Understanding diffusion MR imaging techniques: From scalar diffusion-weighted imaging to diffusion tensor imaging and beyond. Radiographics 2006, 26, 205-223. [CrossRef]

102. Le Bihan, D.; Mangin, J.-F.; Poupon, C.; Clark, C.A.; Pappata, S.; Molko, N.; Chabriat, H. Diffusion Tensor Imaging: Concepts and Applications. J Magn. Reson. Imaging 2001, 13, 534-546. [CrossRef] [PubMed]

103. Thaler, H.T.; Ferber, P.W.; Rottenberg, D.A. A Statistical Method for Determining the Proportions of Gray Matter, White Matter, and CSF using Computed Tomography. Neuroradiology 1978, 16, 133-135. [CrossRef] [PubMed]

104. Basser', P.J. New Histological and Physiological Stains Derived from Diffusion-Tensor MR Images. Ann. N. Y. Acad. Sci. 1997, 820, 123-138. [CrossRef] [PubMed]

105. Pierpaoli, C.; Basser, P.J. Toward a Quantitative Assessment of Diffusion Anisotropy. Magn. Reson. Med. 1996, 36, 893-906. [CrossRef] [PubMed]

106. Makris, N.; Worth, A.J.; Sorensen, A.G.; Papadimitriou, G.M.; Reese, T.G.; Wedeen, V.J.; Davis, T.L.; W Stakes, S.J.; Caviness, V.S.; Kaplan, E.; et al. Morphometry of In Vivo Human White Matter Association Pathways with Diffusion-Weighted Magnetic Resonance Imaging. Ann. Neurol. 1997, 42, 951-962. [CrossRef]

107. Chanraud, S.; Zahr, N.; Sullivan, E.V.; Pfefferbaum, A. MR Diffusion Tensor Imaging: A Window into White Matter Integrity of the Working Brain. Neuropsychol. Rev. 2010, 20, 209-225. [CrossRef] [PubMed]

108. Thomason, M.E.; Dougherty, R.F.; Colich, N.L.; Perry, L.M.; Rykhlevskaia, E.I.; Louro, H.M.; Hallmayer, J.F.; Waugh, C.E.; Bammer, R.; Glover, G.H.; et al. COMT genotype affects prefrontal white matter pathways in children and adolescents. Neuroimage 2010, 53, 926-934. [CrossRef]

109. Gupta, A.; Shah, A.; Young, R.J.; Holodny, A.I. Imaging of brain tumors: Functional magnetic resonance imaging and diffusion tensor imaging. Neuroimaging Clin. N. Am. 2010, 20, 379-400. [CrossRef]

110. Byrnes, T.J.D.; Barrick, T.R.; Bell, B.A.; Clark, C.A. Diffusion tensor imaging discriminates between glioblastoma and cerebral metastases in vivo. NMR Biomed. 2011, 24, 54-60. [CrossRef]

111. Sinha, S.; Bastin, M.E.; Whittle, I.R.; Wardlaw, J.M. Diffusion tensor MR imaging of high-grade cerebral gliomas. Am. J. Neuroradiol. 2002, 23, 520-527.

112. Beppu, T.; Inoue, T.; Shibata, Y.; Kurose, A.; Arai, H.; Ogasawara, K.; Ogawa, A.; Nakamura, S.; Kabasawa, H. Measurement of fractional anisotropy using diffusion tensor MRI in supratentorial astrocytic tumors. J. Neurooncol. 2003, 63, 109-116. [CrossRef]

113. White, M.L.; Zhang, Y.; Yu, F.; Jaffar Kazmi, S.A. Diffusion tensor MR imaging of cerebral gliomas: Evaluating fractional anisotropy characteristics. Am. J. Neuroradiol. 2011, 32, 374-381. [CrossRef] 
114. Toh, C.H.; Castillo, M.; Wong, A.M.C.; Wei, K.C.; Wong, H.F.; Ng, S.H.; Wan, Y.L. Primary cerebral lymphoma and glioblastoma multiforme: Differences in diffusion characteristics evaluated with diffusion tensor imaging. Am. J. Neuroradiol. 2008, 29, 471-475. [CrossRef]

115. Stadlbauer, A.; Ganslandt, O.; Buslei, R.; Hammen, T.; Gruber, S.; Moser, E.; Buchfelder, M.; Salomonowitz, E.; Nimsky, C. Gliomas: Histopathologic evaluation of changes in directionality and magnitude of water diffusion at diffusion-tensor MR imaging. Radiology 2006, 240, 803-810. [CrossRef] [PubMed]

116. Wang, W.; Steward, C.E.; Desmond, P.M. Diffusion tensor imaging in glioblastoma multiforme and brain metastases: The role of p, q, L, and fractional anisotropy. Am. J. Neuroradiol. 2009, 30, 203-208. [CrossRef] [PubMed]

117. Lu, S.; Ahn, D.; Johnson, G.; Law, M.; Zagzag, D.; Grossman, R.I. Diffusion-tensor MR imaging of intracranial neoplasia and associated peritumoral edema: Introduction of the tumor infiltration index. Radiology 2004, 232, 221-228. [CrossRef] [PubMed]

118. Tsuchiya, K.; Fujikawa, A.; Nakajima, M.; Honya, K. Differentiation between solitary brain metastasis and high-grade glioma by diffusion tensor imaging. Br. J. Radiol. 2005, 78, 533-537. [CrossRef] [PubMed]

119. Jiang, R.; Du, F.Z.; He, C.; Gu, M.; Ke, Z.W.; Li, J.H. The value of diffusion tensor imaging in differentiating high-grade gliomas from brain metastases: A systematic review and meta-analysis. PLoS ONE 2014, 9, e112550. [CrossRef]

120. Skogen, K.; Schulz, A.; Helseth, E.; Ganeshan, B.; Dormagen, J.B.; Server, A. Texture analysis on diffusion tensor imaging: Discriminating glioblastoma from single brain metastasis. Acta Radiol. 2019, 60, 356-366. [CrossRef] [PubMed]

121. Tsolaki, E.; Svolos, P.; Kousi, E.; Kapsalaki, E.; Fountas, K.; Theodorou, K.; Tsougos, I. Automated differentiation of glioblastomas from intracranial metastases using 3T MR spectroscopic and perfusion data. Int. J. Comput. Assist. Radiol. Surg. 2013, 8, 751-761. [CrossRef]

122. Jespersen, S.N.; Bjarkam, C.R.; Nyengaard, J.R.; Chakravarty, M.M.; Hansen, B.; Vosegaard, T.; Østergaard, L.; Yablonskiy, D.; Nielsen, N.C.; Vestergaard-Poulsen, P. Neurite density from magnetic resonance diffusion measurements at ultrahigh field: Comparison with light microscopy and electron microscopy. NeuroImage 2010, 49, 205-216. [CrossRef]

123. Zhang, H.; Schneider, T.; Wheeler-Kingshott, C.A.; Alexander, D.C. NODDI: Practical in vivo neurite orientation dispersion and density imaging of the human brain. Neuroimage 2012, 61, 1000-1016. [CrossRef]

124. Kaden, E.; Knösche, T.R.; Anwander, A. Parametric spherical deconvolution: Inferring anatomical connectivity using diffusion MR imaging. Neuroimage 2007, 37, 474-488. [CrossRef]

125. Jacobs, B.; Driscoll, L.; Schall, M. Life-span dendritic and spine changes in areas 10 and 18 of human cortex: A quantitative golgi study. J. Comp. Neurol. 1997, 386, 661-680. [CrossRef]

126. Nyúl, L.G.; Udupa, J.K. MR image analysis in multiple sclerosis. Neuroimaging Clin. N. Am. 2000, 10, 799-815.

127. Bruijn, L.I.; Miller, T.M.; Cleveland, D.W. Unraveling the mechanisms involved in motor neuron degeneration in ALS. Annu. Rev. Neurosci. 2004, 27, 723-749. [CrossRef] [PubMed]

128. Paula-Barbosa, M.M.; Mota Cardoso, R.; Guimaraes, M.L.; Cruz, C. Dendritic degeneration and regrowth in the cerebral cortex of patients with Alzheimer's disease. J. Neurol. Sci. 1980, 45, 129-134. [CrossRef]

129. Mao, J.; Zeng, W.; Zhang, Q.; Yang, Z.; Yan, X.; Zhang, H.; Wang, M.; Yang, G.; Zhou, M.; Shen, J. Differentiation between high-grade gliomas and solitary brain metastases: A comparison of five diffusion-weighted MRI models. BMC Med. Imaging 2020, 20, 124. [CrossRef] [PubMed]

130. Jensen, J.H.; Helpern, J.A. MRI quantification of non-Gaussian water diffusion by kurtosis analysis. NMR Biomed. 2010, 23, 698-710. [CrossRef]

131. Buonocore, M.H.; Maddock, R.J. Magnetic resonance spectroscopy of the brain: A review of physical principles and technical methods. Rev. Neurosci. 2015, 26, 609-632. [CrossRef] [PubMed]

132. Thomsen, C.; Jensen, K.E.; Achten, E.; Henriksen, O. In vivo magnetic resonance imaging and 31P spectroscopy of large human brain tumours at 1.5 tesla. Acta Radiol. 1988, 29, 77-82. [CrossRef]

133. Opstad, K.S.; Murphy, M.M.; Wilkins, P.R.; Bell, B.A.; Griffiths, J.R.; Howe, F.A. Differentiation of metastases from high-grade gliomas using short echo time $1 \mathrm{H}$ spectroscopy. J. Magn. Reson. Imaging 2004, 20, 187-192. [CrossRef] [PubMed]

134. Tsougos, I.; Svolos, P.; Kousi, E.; Fountas, K.; Theodorou, K.; Fezoulidis, I.; Kapsalaki, E. Differentiation of glioblastoma multiforme from metastatic brain tumor using proton magnetic resonance spectroscopy, diffusion and perfusion metrics at $3 \mathrm{~T}$. Cancer Imaging 2012, 12, 423-436. [CrossRef]

135. Knopp, E.A.; Cha, S.; Johnson, G.; Mazumdar, A.; Golfinos, J.G.; Zagzag, D.; Miller, D.C.; Kelly, P.J.; Kricheff, I.I. Glial neoplasms: Dynamic contrast-enhanced T2*-weighted MR imaging. Radiology 1999, 211, 791-798. [CrossRef] [PubMed]

136. Cho, S.K.; Na, D.G.; Ryoo, J.W.; Roh, H.G.; Moon, C.H.; Byun, H.S.; Kim, J.H. Perfusion MR Imaging: Clinical Utility for the Differential Diagnosis of Various Brain Tumors. Korean J. Radiol. 2002, 3, 171-179. [CrossRef] [PubMed]

137. Ishimaru, H.; Morikawa, M.; Iwanaga, S.; Kaminogo, M.; Ochi, M.; Hayashi, K. Differentiation between high-grade glioma and metastatic brain tumor using single-voxel proton MR spectroscopy. Eur. Radiol. 2001, 11, 1784-1791. [CrossRef] [PubMed]

138. Kimura, T.; Sako, K.; Gotoh, T.; Tanaka, K.; Tanaka, T. In vivo single-voxel proton MR spectroscopy in brain lesions with ring-like enhancement. NMR Biomed. 2001, 14, 339-349. [CrossRef] [PubMed]

139. McBride, D.Q.; Miller, B.L.; Nikas, D.L.; Buchthal, S.; Chang, L.; Chiang, F.; Booth, R.A. Analysis of brain tumors using $1 \mathrm{H}$ magnetic resonance spectroscopy. Surg. Neurol. 1995, 44, 137-144. [CrossRef] 
140. Bruhn, H.; Frahm, J.; Gyngell, M.L.; Merboldt, K.D.; Hanincke, W.; Sauter, R.; Hamburger, C. Noninvasive differentiation of tumors with use of localized H-1 MR spectroscopy in vivo: Initial experience in patients with cerebral tumors. Radiology 1989, 172, 541-548. [CrossRef]

141. Al-Okaili, R.N.; Krejza, J.; Wang, S.; Woo, J.H.; Melhem, E.R. Advanced MR imaging techniques in the diagnosis of intraaxial brain tumors in adults. Radiographics 2006, 26, 173-189. [CrossRef]

142. Sijens, P.E.; Knopp, M.V.; Brunetti, A.; Wicklow, K.; Alfano, B.; Bachert, P.; Sanders, J.A.; Stillman, A.E.; Kett, H.; Sauter, R.; et al. 1H MR Spectroscopy in Patients with Metastatic Brain Tumors: A Multicenter Study. Magn. Reson. Med. 1995, 33, 818-826. [CrossRef]

143. Poptani, H.; Gupta, R.K.; Roy, R.; Pandey, R.; Jain, V.K.; Chhabra, D.K. Characterization of Intracranial Mass Lesions with In Vivo Proton MR Spectroscopy. Am. J. Neuroradiol. 1995, 16, 1593-1603. [PubMed]

144. Fulham, M.J.; Bizzi, A.; Dietz, M.J.; Shih, H.H.L.; Raman, R.; Sobering, G.S.; Frank, J.A.; Dwyer, A.J.; Alger, J.R.; Di Chiro, G. Mapping of brain tumor metabolites with proton MR spectroscopic imaging: Clinical relevance. Radiology 1992, 185, 675-686. [CrossRef]

145. Dikaios, N. Deep learning magnetic resonance spectroscopy fingerprints of brain tumours using quantum mechanically synthesised data. NMR Biomed. 2021, 34, e4479. [CrossRef] [PubMed]

146. Lameka, K.; Farwell, M.D.; Ichise, M. Positron Emission Tomography. Handb. Clin. Neurol. 2016, 135, 209-227. [PubMed]

147. Spanoudaki, V.C.; Levin, C.S. Photo-detectors for time of flight positron emission tomography (ToF-PET). Sensors 2010, 10, 10484-10505. [CrossRef]

148. Purandare, N.C.; Puranik, A.; Shah, S.; Agrawal, A.; Gupta, T.; Moiyadi, A.; Shetty, P.; Shridhar, E.; Jalali, R.; Rangarajan, V. Common malignant brain tumors: Can 18 F-FDG PET/CT aid in differentiation? Nucl. Med. Commun. 2017, 38, 1109-1116. [CrossRef] [PubMed]

149. Holzgreve, A.; Albert, N.L.; Galldiks, N.; Suchorska, B. Use of pet imaging in neuro-oncological surgery. Cancers 2021, 13, 2093. [CrossRef]

150. Rahmim, A.; Zaidi, H. PET versus SPECT: Strengths, limitations and challenges. Nucl. Med. Commun. 2008, $29,193-207$. [CrossRef]

151. Beauchesne, P.; Soler, C.; Mosnier, J.F. Diffuse vertebral body metastasis from a glioblastoma multiforme: A technetium-99m Sestamibi single-photon emission computerized tomography study: Case report. J. Neurosurg. 2000, 93, 887-890. [CrossRef]

152. Doishita, S.; Sakamoto, S.; Yoneda, T.; Uda, T.; Tsukamoto, T.; Yamada, E.; Yoneyama, M.; Kimura, D.; Katayama, Y.; Tatekawa, H.; et al. Differentiation of brain metastases and gliomas based on color map of phase difference enhanced imaging. Front. Neurol. 2018, 9, 788. [CrossRef]

153. Sachdeva, J.; Kumar, V.; Gupta, I.; Khandelwal, N.; Ahuja, C.K. Segmentation, feature extraction, and multiclass brain tumor classification. J. Digit. Imaging 2013, 26, 1141-1150. [CrossRef] [PubMed]

154. Zacharaki, E.; Wang, S.; Chawla, S.; Yoo, D.S.; Wolf, R.; Melhem, E.R.; Davatzikos, C. Classification of brain tumor type and grade using MRI texture and shape in a machine learning scheme. Magn. Reson. Med. 2009, 62, 1609-1618. [CrossRef]

155. Yamashita, K.; Yoshiura, T.; Arimura, H.; Mihara, F.; Noguchi, T.; Hiwatashi, A.; Togao, O.; Yamashita, Y.; Shono, T.; Kumazawa, S.; et al. Performance evaluation of radiologists with artificial neural network for differential diagnosis of intra-axial cerebral tumors on MR images. Am. J. Neuroradiol. 2008, 29, 1153-1158. [CrossRef]

156. Alcaide-Leon, P.; Dufort, P.; Geraldo, A.F.; Alshafai, L.; Maralani, P.J.; Spears, J.; Bharatha, A. Differentiation of enhancing glioma and primary central nervous system lymphoma by texture-based machine learning. Am. J. Neuroradiol. 2017, 38, 1145-1150. [CrossRef] [PubMed]

157. Artzi, M.; Bressler, I.; Ben Bashat, D. Differentiation between glioblastoma, brain metastasis and subtypes using radiomics analysis. J. Magn. Reson. Imaging 2019, 50, 519-528. [CrossRef] [PubMed]

158. Bae, S.; An, C.; Soo Ahn, S.; Kim, H.; Han, K.; Wook Kim, S.; Eun Park, J.; Sung Kim, H.; Lee, S.-K. Robust performance of deep learning for distinguishing glioblastoma from single brain metastasis using radiomic features: Model development and validation. Sci. Rep. 2020, 10, 12110. [CrossRef] [PubMed]

159. Dong, F.; Li, Q.; Jiang, B.; Zhu, X.; Zeng, Q.; Huang, P.; Chen, S.; Zhang, M. Differentiation of supratentorial single brain metastasis and glioblastoma by using peri-enhancing oedema region-derived radiomic features and multiple classifiers. Eur. Radiol. 2020, 30, 3015-3022. [CrossRef] [PubMed]

160. Qian, Z.; Li, Y.; Wang, Y.; Li, L.; Li, R.; Wang, K.; Li, S.; Tang, K.; Zhang, C.; Fan, X.; et al. Differentiation of glioblastoma from solitary brain metastases using radiomic machine-learning classifiers. Cancer Lett. 2019, 451, 128-135. [CrossRef]

161. Tateishi, M.; Nakaura, T.; Kitajima, M.; Uetani, H.; Nakagawa, M.; Inoue, T.; Kuroda, J.I.; Mukasa, A.; Yamashita, Y. An initial experience of machine learning based on multi-sequence texture parameters in magnetic resonance imaging to differentiate glioblastoma from brain metastases. J. Neurol. Sci. 2020, 410, 116514. [CrossRef]

162. Swinburne, N.C.; Schefflein, J.; Sakai, Y.; Oermann, E.K.; Titano, J.J.; Chen, I.; Tadayon, S.; Aggarwal, A.; Doshi, A.; Nael, K. Machine learning for semi automated classification of glioblastoma, brain metastasis and central nervous system lymphoma using magnetic resonance advanced imaging. Ann. Transl. Med. 2019, 7, 232. [CrossRef]

163. Petrujkić, K.; Milošević, N.; Rajković, N.; Stanisavljević, D.; Gavrilović, S.; Dželebdžić, D.; Ilić, R.; Di Ieva, A.; Maksimović, R. Computational quantitative MR image features-A potential useful tool in differentiating glioblastoma from solitary brain metastasis. Eur. J. Radiol. 2019, 119, 108634. [CrossRef] [PubMed] 
164. Yang, G.; Jones, T.L.; Howe, F.A.; Barrick, T.R. Morphometric model for discrimination between glioblastoma multiforme and solitary metastasis using three-dimensional shape analysis. Magn. Reson. Med. 2016, 75, 2505-2516. [CrossRef] [PubMed]

165. Turcan, S.; Rohle, D.; Goenka, A.; Walsh, L.A.; Fang, F.; Yilmaz, E.; Campos, C.; Fabius, A.W.M.; Lu, C.; Ward, P.S.; et al. IDH1 mutation is sufficient to establish the glioma hypermethylator phenotype. Nature 2012, 483, 479-483. [CrossRef] [PubMed]

166. Noorani, I.; De La Rosa, J.; Choi, Y.; Strong, A.; Ponstingl, H.; Vijayabaskar, M.S.; Lee, J.; Lee, E.; Richard-Londt, A.; Friedrich, M.; et al. PiggyBac mutagenesis and exome sequencing identify genetic driver landscapes and potential therapeutic targets of EGFR-mutant gliomas. Genome Biol. 2020, 21, 1-36.

167. Rathore, S.; Akbari, H.; Rozycki, M.; Abdullah, K.G.; Nasrallah, M.P.; Binder, Z.A.; Davuluri, R.V.; Lustig, R.A.; Dahmane, N.; Bilello, M.; et al. Radiomic MRI signature reveals three distinct subtypes of glioblastoma with different clinical and molecular characteristics, offering prognostic value beyond IDH1. Sci. Rep. 2018, 8, 5087. [CrossRef] [PubMed]

168. Bakas, S.; Akbari, H.; Pisapia, J.; Martinez-Lage, M.; Rozycki, M.; Rathore, S.; Dahmane, N.; O’Rourke, D.M.; Davatzikos, C. In vivo detection of EGFRvIII in glioblastoma via perfusion magnetic resonance imaging signature consistent with deep peritumoral infiltration: The $\varphi$-index. Clin. Cancer Res. 2017, 23, 4724-4734. [CrossRef] [PubMed] 